1. COMENTARIO MONOGRAFICO

\title{
LA FACULTAD DE SUSPENSION \\ $Y$ DEMOLICION DE OBRAS REALIZADAS SIN LICENCIA O CONTRAVINIENDO LAS CONDICIONES DE LA LICENCIA OTORGADA
}

351.778.523:35.078

\section{por \\ Nemesio Rodríguez Moro}

La regulación que sobre esta facultad se establece en el artículo 171 de la Ley del Suelo de 12 de mayo de 1956 viene dando lugar a interpretaciones diversas, incluso por los Tribunales. Por eso parece conveniente poner de relieve con un comentario específico la doctrina establecida por el Tribunal Supremo en su sentencia de 25 de junio de 1973 (Ar. 2.877) en ponencia del Excmo. Sr. D. Félix Fernández Tejedor, que, revocando la del Tribunal inferior, declara errónea la tesis que éste sustentaba en torno a la interpretación del párrafo $4 .^{\circ}$ del artículo 171 de la Ley del Suelo.

Este artículo dispone lo siguiente:

«1. El Ayuntamiento, la Comisión Provincial de Urbanismo o sus respectivos Presidentes dispondrán la suspensión de los actos relacionados en el artículo 165 que se efectuaren sin licencia u orden de ejecución o sin ajustarse a las condiciones legítimas señaladas.

2. En el plazo de dos meses, el organismo competente para otorgar la licencia efectuará la adecuada comprobación y acordará: 
a) Demoler las obras e impedir definitivamente los usos cuya licencia hubiera sido improcedente o no se ajustaren a las citadas condiciones; y

b) Legalizar las obras y autorizar los usos que se amoldaren a aquéllas.

3. Si se tratare de parcelaciones sin licencia o sin ajustarse a la otorgada, cualquiera de las autoridades $u$ organismos a que se refiere el párrafo 1 prohibirá, además, todo intento de urbanizar o edificar los terrenos, dispondrá la destrucción de lo realizado y podrá expropiarlos sin el requisito de formulación de previo proyecto.

4. Si no se adoptare el acuerdo en el plazo señalado, quedará levantada la suspensión.»

Aunque el artículo transcrito origina otros problemas de interpretación, no vamos a ocuparnos ahora más que del principal a que da lugar la redacción del párrafo $4 .^{\circ}$ del mismo. ¿Puede el órgano competente llevar adelante su actividad en orden a demoler lo indebidamente realizado después de pasar los dos meses de haber sido suspendida la actuación urbanística del particular que no tenía la licencia reglamentaria para ello o que había infringido las condiciones legales que en aquélla se imponían o, por el contrario, se halla la Administración impedida legalmente para acordar la demolición si han transcurrido más de dos meses desde que se decretó la suspensión de la obra? Los antecedentes prácticos de la sentencia mencionada son, en apretada síntesis, los siguientes:

1. Un particular pide al Ayuntamiento de $\mathrm{X}$ que se le otorgue una licencia de obras que, en efecto, después de los preceptivos informes le es concedida.

2. Al verificarse la oportuna inspección se comprueba que la construcción no se ha acomodado a las condiciones impuestas en la licencia.

3. El Ayuntamiento declara en suspenso la licencia, y, cuando ya ha transcurrido con exceso el plazo de dos meses, dicta resolución mandando demoler lo indebidamente construido.

4..$^{\circ}$ Denegada la reposición, el interesado acude al Tribunal Contencioso-administrativo competente, quien declara nulo el acto administrativo municipal que ordenaba la demolición. 
5. Apelada la sentencia por el Ayuntamiento ante el Tribunal Supremo, éste revoca la sentencia del inferior por considerar errónea la tesis sustentada, declarando que el acto municipal por el que se imponía la demolición de lo indebidamento construido se hallaba ajustado a derecho.

Vemos ahora algunas de las afirmaciones de mayor interés de la sentencia del Tribunal Supremo.

Primera. La facultad que otorga el artículo 171 para demoler lo indebidamente hecho no es una facultad excepcional y restringi$d a$, sino que ella es normal y consecuencia de la exigencia de que la norma sea cumplida.

Es de razón que si a la autoridad competente le está conferida por la Ley no sólo la facultad, sino la obligación de hacer que la norma se cumpla, es una consecuencia inmediata el que no deba considerarse como una facultad excepcional y restringida, con los estrechos límites de actuación que ello comporta, sino, por el contrario, tal facultad ha de estimarse como normal y en plenitud de ejercicio en tanto que el propio legislador, de una manera expresa y categórica, no establezca unos límites temporales a tal actuación de la Administración. Y, en consecuencia, si, como dispone el artículo 171 de la Ley del Suelo, la Administración ante una obra que se realiza sin la debida licencia o con infracción de las condiciones legales establecidas en la misma ha de poner en acción una medida cautelar, la suspensión de la obra, teniendo luego un plazo de dos meses, durante el cual se mantiene legalmente la suspensión, para poder realizar las inspecciones y comprobaciones precisas en orden a dictar una resolución que puede ser de legalización de la obra o de demolición de la misma, parece de razón que si ha dejado pasar ese plazo de dos meses sin dictar tal resolución, la consecuencia sea la de que la medida cautelar quede sin efecto y, en consecuencia, levantada la suspensión, pero sin que ello sea óbice para que la Administración pueda luego declarar la legalización de la situación o la obligación de que tal obra sea demolida por no ajustarse a la norma jurídica. Claro que ello sin perjuicio de que si la demora en adoptar tal resolución ha originado daños y perjuicios al particular pueda éste exigir la pertinente indemnización, ya que podrían darse los supuestos a que se refieren los artículos 
407 y siguientes de la Ley de Régimen local vigente en orden a la responsabilidad de la Administración municipal.

Segunda. Que el párrafo $4 .^{\circ}$ del artículo 171 de la Ley del Suelo solamente dispone que la suspensión quede levantada si transcurre el plazo de dos meses sin adoptarse resolución de legalización o demolición.

Es claro el precepto legal al efecto, y, por ello, resulta erróneo dar al precepto legal una extensión que no tiene, con la consecuencia, ya antes indicada, de producir una limitación en la facultad normal de la Administración en orden a velar por el cumplimiento del ordenamiento urbanístico.

$\mathrm{Si}$ el legislador hubiera querido tal cosa, lo hubiera expresado así, y es indudable que es muy distinto el que cese la medida cautelar de suspensión al transcurrir dos meses, a que se imponga una prohibición a la Administración para que pueda declarar la legalización de las obras o la demolición de lo indebidamente hecho, situación ésta a que debe llegarse en definitiva siempre que se inicie un procedimiento para esclarecer si una obra se hace o no con la licencia reglamentaria o si se ajusta o no a los términos en que la licencia fue otorgada.

$\mathrm{Si}$, como antes se dice, el precepto es claro y de su expresión literal sólo puede inferirse que lo que queda sin efecto al pasar los dos meses es la suspensión, no cabe extender más allá lo dispuesto en el párrafo $4 .^{\circ}$ del artículo 171 de la Ley del Suelo.

Así, pues, el particular interesado puede considerar terminado el plazo de suspensión al transcurrir los dos meses desde que tal suspensión fue decretada, ya que por ministerio de la Ley la suspensión tiene esa limitación de plazo y el precepto obliga tanto al administrado como a la Administración.

Tercera. La demora de la Administración en adoptar la resolución de demolición puede dar origen a responsabilidad administrativa.

Al terminarse el plazo legal de los dos meses de una suspensión, medida cautelar en tanto se comprueba si existe o no otorgada la licencia o si la obra se realiza infringiendo las condiciones de la licencia otorgada, el particular puede proseguir ejecutando la obra; 
y si después la Administración resuelve que la obra debe ser demolida, es indudable que pueden haberse producido daños y perjuicios al particular, ya que él podía legalmente continuarla después de transcurridos los dos meses de suspensión, y la Administración estaba obligada a adoptar la resolución que procediera dentro del plazo de los dos meses fijado por la Ley.

Se ha producido un funcionamiento anormal o deficiente de los servicios administrativos, es decir, una actuación incorrecta de la gestión administrativa, por cuanto la Administración venía obligada ope legis a adoptar la resolución de demoler dentro de los dos meses, pudiendo entrar en juego la responsabilidad a que se refieren los artículos 405 y siguientes de la Ley de Régimen local y 121 y 122 de la Ley de Expropiación forzosa y su Reglamento, sin que sea éste el momento de entrar en la cuestión, hoy sometida a discusión entre los tratadistas y aún no resuelta de modo unánime en las sentencias de los Tribunales, del valor prioritario de los preceptos antes citados, pues en tanto hay quien sustenta que las normas contenidas en la Ley y Reglamento de Expropiación forzosa tienen prelación en orden a la exigencia de responsabilidad de la Administración local, quedando en segundo lugar la Ley de Régimen local y el Reglamento de Organización y Funcionamiento de las Corporaciones locales, por el contrario, otras opiniones se inclinan a dar preferencia a la normativa de Régimen local.

Estas son las principales cuestiones a que se refiere la sentencia del Tribunal Supremo que es ahora objeto de comentario, aduciendo razonamientos múltiples, según puede verse en los considerandos de la misma que a continuación se transcriben y que son del tenor literal siguiente:

Considerando: Que de este modo queda perfectamente delimitado el ámbito de esta apelación que se contrae solamente y con exclusión de cualquier otra cuestión que pudiera entenderse planteada en la demanda, a juzgar sobre dichos dos extremos; esto es, si es o no ajustada a derecho la resolución municipal - Decreto de la Alcaldía de San Sebastián, fecha 2 de marzo de 1968- que ordenó la demolición de las obras de elevación realizadas en la cubierta de la casa núm. 14 de la calle de San Ignacio de Loyola, esquina a la Plaza del Buen Pastor de aquella ciudad, y en caso de que no lo fuere, si ha lugar o no a declarar a favor de los recurrentes el derecho a la indemnización de daños y perjuicios, petición única en la que éstos insisten en sus alegaciones como apelantes, demostrando de este modo su conformidad y aquiescencia con los demás particulares del fallo. 
CONSIDERANDO: Que previamente a los razonamientos que sirvieron de base a la Sala de lo Contencioso de la Audiencia de Pamplona para llegar a formular una declaración de nulidad del Decreto de la Alcaldía de San Sebastián, fecha 2 de marzo de 1968, que ordenó la demolición de las obras objeto de este recurso y autorizó a los beneficiarios de la licencia para proseguirlos, se reconoció por el mismo Tribunal «a quo» en su considerando tercero: 1) que la licencia concedida al señor $C$. autorizaba a éste solamente a la reparación de la cubierta, mediante la simple reposición de materiales, con la prohibición de alterar el perfil o altura máxima fijada por las Ordenanzas y de efectuar modificación alguna en su estructura; 2) que el señor C. aceptó este claro contenido y alcance de la licencia, y la consintió en los términos en que fue concedida, al no entablar contra ella reclamación ni recurso alguno; 3) que no obstante este consentimiento infringió de modo claro, inequívoco y voluntario las condiciones impuestas por la licencia y realizó una obra no de simple reparación y sin modificación alguna, únicas obras a las que aquélla le autorizaba, sino de transformación profunda de la cubierta con elevación de su perfil en una altura de 1,20 metros contra las prohibiciones de las Ordenanzas y lo dispuesto en la licencia.

Considerando: Que a pesar de esta clara y manifiesta infracción de las condiciones legítimas señaladas en la licencia, la Sala de instancia ha declarado nula la orden de demolición de las obras ilegítimamente realizadas, dictada por la Alcaldía de San Sebastián, y además ha autorizado al beneficiario de la licencia para proseguirlas hasta su total conclusión, resolución adoptada a través del siguiente razonamiento: A) Estima con acierto correcta la resolución municipal de suspensión de dichas obras, adoptada con carácter previo a la orden de demolición y en función del artículo 171-1 de la Ley del Suelo. B) Entiende, también acertadamente, que el órgano municipal, acordada la suspensión, debió proceder como ordena el precepto citado núm. 2, a resolver dentro del plazo de dos meses, desde la fecha de aquel acuerdo, la demolición o legalización de la obra. C) Transcurrido el plazo mencionado de dos meses sin que el Ayuntamiento o la Alcaldía resolviese una cosa u otra, estima la Sala de instancia, y aquí se produce con error, que por efecto de lo dispuesto en el núm. 4 del mencionado artículo 171 de la Ley del Suelo, el órgano municipal no pudo ya acordar la demolición, y la obra debe legalizarse.

Considerando: Que la precedente declaración de la sentencia apelada tiene su base en la errónea interpretación de los propios preceptos jurídicos que el considerando quinto invoca como fundamento de ella, así como en la preterición de otros que han debido ser tenidos en cuenta y no lo han sido por el Juzgado de instancia. Entre los primeros, esta Sala señala: A) No está justificada la afirmación que hace la sentencia de primera instancia en el sentido de que la potestad de la Administración conferida por el artículo 171 de la Ley del Suelo, para ordenar la demolición de obras realizadas con manifiesta infracción de las condi- 
ciones legitimas señaladas en la licencia, sea de carácter excepcional y haya de ser aplicada restrictivamente. Lejos de ello es consecuencia normal de la propia eficacia de la norma. En otro caso, se facilitaria la consumación de cualquier propósito de construir anárquicamente con desprecio de las normas urbanisticas (vulnerando tanto las Ordenanzas como las condiciones legitimas señaladas en las licencias), ya que si se supone configurada la potestad administrativa para evitar tales excesos de un modo excepcional y restringido y, por tanto, débil, surgirian o se provocaría en ciertos casos la concurrencia de multitud de circunstancias que dificultarian su ejercicio. Ello atentaría evidentemente al principio de eficacia del derecho urbanístico, garantía de intereses generales de suma $y$, a veces, decisiva importancia y trascendencia que deben ser amparados enérgicamente, $y$ en plano de prevalencia sobre el mero interés particular. Asi pues ninguna interpretación restrictiva ni extensiva debe ser hecha de tal potestad, sino que por el contrario debe ser entendida de modo que naturalmente sirva con eficacia a los intereses generales en cuya protección se concede sin lesio nar, en efecto, los legitimos de los particulares, pero no sólo en tanto éstos sean intereses verdaderamente legitimos, y no lo son cuando contradicen abiertamente, como en este caso ocurre, las Ordenanzas (norma municipal urbanistica con efecto de obligar), de una parte, y de otra, los términos precisos y claros de una licencia, que al lado de una permisión contiene una prohibición expresa que ha sido violada. B) La errónea tesis de la sentencia apelada, que esta Sala rebate en el apartado anterior (interpretación restrictiva de la potestad administrativa de ordenar la demolición de las obras no ajustadas a las condiciones legitimas señaladas en la licencia), arrastra al Juzgador de instancia a interpretar congruentemente con tan erróneo criterio, y por tanto, con el mismo desacierto, el párrafo 4 del artículo 171 de la Ley del Suelo. Dice este párrafo que "si no se adoptare el acuerdo (de legalización o demolición de la obra) en el plazo señalado quedará levantada la suspensión». Y la sentencia añade: "... lo que es indicativo que automáticamente queda levantada la suspensión y lógicamente quedan ya sin posibilidad válida de emanación los acuerdos de demolición o legalización que sólo pueden adoptarse en tanto subsista la paralización de las obras».

CONSIDERANDO: Que si interpretamos literalmente la anterior expresión del fallo anulatorio y no cabe interpretación de otro modo, habrá de concluirse en que transcurridos, desde el acuerdo de suspensión, dos meses, sin que recaiga otro ordenando la demolición o la legalización de la obra, se produciría una situación no sólo original y contradictoria, sino también carente de lógica, pues no solamente no podría en tal evento dictarse acuerdo de demolición, sino tampoco de legalización, hipótesis a todas luces absurda, que llevaría a la no menos absurda e inconcebible consecuencia que legalmente lo mismo hubiera dado lugar a un fallo anulatorio en esta Jurisdicción la resolución que ordenó 
la demolición, que la que pudo haberse dictado acordando la legalización de la obra.

CONSIDERANDO: Que lo realmente cierto y evidente es: primero, que la Ley no sólo declara alzado el efecto de suspensión cuando ha transcurrido el plazo de dos meses sin resolver; segundo, que es muy diferente y están situados en distinto plano jurídico el efecto suspensivo de la obra y la resolución definitivamente sancionadora de su legalidad - ilegalidad; tercero, que es un imperativo lógico que como inevitable exigencia del principio de seguridad juridica ha de llegar un momento en que deba ser declarada la obra legal o ilegal; cuarto, que si el levantamiento de la suspensión llevase consigo automáticamente un efecto convalidatorio, la Ley lo expresaría asi, y del mismo modo en caso contrario; quinto, que consiguientemente, no sólo no viola ningún precepto legal, sino que jurídicamente es irreprochable y lógico que la Administración no solamente pueda, sino que también deba, aun transcurrido dicho plazo de dos meses, declarar legalizada la obra, si ello procediere y fuese posible por atentar solamente a los términos permisivos de la licencia pero no a las normas superiores, Ley u Ordenanza y ordenar su demolición ( $y$ esto es sanción inevitable si, como en este caso ocurre, vulneta no sólo las condiciones legitimas de la licencia, sino también las Ordenanzas) sin otra particularidad que la que pudiera derivarse de lo dispuesto en el artículo 49 de la Ley de Procedimiento administrativo para las actuaciones fuera de plazo (acto válido, y eventual responsabtlidad de la Administración o funcionario causante de la demora), y sexto, que, estableciendo también el artículo 16 del Reglamento de Servicios de las Corporaciones locales, sanción de ineficacia de las licencias cuando los términos de ésta han sido rebasados, tal precepto quedaría implacablemente en el vacío de admitirse la tesis del recurrente.

ConsIDERANDo: Que rechazados ya los razonamientos que sirvieron de fundamento al Tribunal inferior para declarar la nulidad de la resolución municipal recurrida y autorizar como consecuencia la continuación de la obra, merece aún subrayarse la gravedad y peligro de tal criterio, que si prevaleciese vendría a constituir una permisión incondicionada a cualquier constructor infractor de las normas urbanisticas señaladas en una licencia, para continuar edificando con carácter indefinido, acumulando infracción tras infracción, pues aceptada la tesis mantenida por el Tribunal inferior en el sentido de que transcurrido el plazo de dos meses desde el acuerdo de suspensión sin haberse resuelto la demolición ésta sería improcedente y ya no habría medio legal hábil para imponerle eficazmente prohibición alguna, fuesen cuales fuesen las infracciones cometidas, y las que continuase cometiendo, ya que quedaria autorizado para la continuación incondicional de la obra.

CONSIDERANDO: Que consecuente con la interpretación y aplicación que en este caso hemos dado al artículo 49 de la Ley de Procedimiento administrativo, y declarada como en la parte dispositiva ha de declarar- 
se la validez del acto impugnado, queda por resolver si procede o no declarar la indemnización de daños y perjuicios, que es la segunda de las cuestiones que se debaten en esta litis, y a tal efecto ha de tenerse en cuenta que la indemnización solicitada por los recurrentes se basa en la presunta nulidad del acto administrativo impugnado. No dándose lugar a esta declaración, sino por el contrario, a la confirmación de la validez de aquél, es evidente que no procede acceder a esta segunda pretensión de los recurrentes, pues le falta la base legal de la que podría derivar o nacer.

Considerando: Que sin perjuicio de la improcedencia de hacer en este Tribunal una declaración efectiva de la obligación de indemnizar, determinada como consecuencia de una nulidad que no se declara, el tema de los daños y perjuicios puede y debe tratarse aquí desde otro punto de vista, el del retraso de la resolución recurrida, dictada con fecha 2 de marzo de 1968 y que regularmente debió ser dictada antes del 18 de diciembre de 1967, pretensión que pudiera tener su base en los artículos 40 de la Ley de Régimen jurídico de la Administración y 378 del Reglamento de Organización, Funcionamiento y Régimen juridico de las Corporaciones locales. De este modo se produjo un período de dos meses y medio durante el cual los recurrentes se encontraron en una situación de indecisión provocada por la demora de la Administración que pudo impedirles la adopción de ciertas medidas en evitación de eventuales daños que dicen sufrió el inmueble. En este sentido es procedente se les reserve la posibilidad del ejercicio efectivo de una acción contra el Ayuntamiento de San Sebastián de resarcimiento de perjuicios, si bien de muy distinto alcance y solamente referidos a los que se demuestre se hayan producido en el inmueble, en el intervalo que medió entre la fecha en que el Ayuntamiento de San Sebastián debió regularmente haber dictado la resolución, 17 de diciembre de 1967, a la fecha en que realmente resolvió, 2 de marzo de 1968, declaración que hubiera podido hacerse en esta sentencia, si el recurrente hubiera planteado en su demanda esta pretensión en tales términos, en lugar de vincularla a la ilegalidad del acto contra el que recurrió.

Considerando: Que por los fundamentos expuestos, es procedente revocar la sentencia dictada en estos autos por el Tribunal inferior en cuanto da lugar a la estimación del recurso y declaración de nulidad de la resolución recurrida, y confirmarla en cuanto deniega la indemnización de daños y perjuicios, sin que se aprecie en ninguno de los apelantes temeridad o mala fe que pudiera determinar condena en costas. 


\section{RESEÑA DE SENTENCIAS}

SUMARIO: I. ASOCIACIONES: JUNTA VECINAL AgROPECUARIA: COMPETENCIA.-II. BIENES: 1. REVERSIÓN: el aRTf́CUlo 97 DEL REgLAMENTO DE Bienes de las Entidades locales. 2 Calificación jurfdica: alteraCIÓN.-III. CONTRATACION ADMINISTRATIVA: 1 GASTOS DE FORMALIZACIÓN DEL CONTRATO. 2. VENTA DE UN TERRENO MUNICIPAL AL ESTADO: CONTRATO ADMINISTRATIVO.-IV. CONTRIBUCION TERRITORIAL: CONSTRUCCIÓN DE EDIFICIO POR UN CONCESIONARIO SOBRE TERRENO MUNICIPAL.-V. EXPROPIACION FORZOSA: 1. INTERESES. 2. JUSTIPRECIO: CRITERIOS DE VALORACIÓN. 3. JUSTIPRECIO: FECHA A LA QUE HA DE REFERIRSE. 4. JUSTIPRECIO: INDEMNIZACIÓN A INQUILINO DE VIVIENDA. 5. JUSTIPRECIO: INDEMNIZACION JUSTA. 6. JUSTIPRECIO: LLEGALidAD APLICABLE: COLEGIO. 7. JUSTIPRECIO: TRASLADO DE NEgocio: PÉRDIDA DE BENEFICIOS. 8. JUSTIPRECIO: TRASLADO DE VAQUERÍA: INDEMNIZACIONES. 9. NECESIDAD DE OCUPACIÓN: NO ES RECURRIBLE EL ACTO MUNICIPAL DEClaRÁNDOla.-VI. FUNCIONARIOS: 1. DERECHOS PASIVOS: aCtUalizaCión DE PENSIONES. 2. ACTUALIZACIÓN DE PENSIONES: CÓMPUTO DE QUINQUENIOS. 3. ACTUALIZACIÓN DE PENSIONES: GRAN INVALIDEZ. 4. DeRECHOS PASIVOS: SERVICIOS EVENTUALES.-VII. GOBERNADORES CIVILES: 1. DEMOLICIÓN DE VIVIENDAS: AUDIENCIA DE LOS INQUILINOS. 2. SANCIONES POR FALTAS A LA MORAL.-VIII. HACIENDAS LOCALES: 1. ARBITRIO DE PLUSVALfA: EXENCIONES: PRIMERAS TRANSMISIONES DE TERRENOS RESULTANTES DE OBRAS DE SANEAMIENTO Y MEJORA INTERIOR DE GRANDES POBLACIONES. 2. ARBITRIO DE PLUSVALfA: INDICE TRIENAL DE Valores; impugnación. 3. ARbitrio de plusvalía: el Instituto NacioNal de Colonización está sujeto al arbitrio. 4. Arbitrio de plusvaLfA: RECTIFICACIÓN DE LIQUIDACIONES; ERROR DE DERECHO. 5. ARBITRIO DE PLUSVALfA: TERRENOS DESTINADOS A ZONAS VERDES Y VIALES EN URBANIZACIÓN. 6. ARbitrio de plusvalfa: terRenos sujetos. 7. ARbitrio de Plusvalfa: terRenos No suJetos; CARGa de la PRUEba. 8. ARbitrio de Plusvalfa: terrenos destinados a viales. 9. ARbitrio de plusvalfa: VIVIENDAS DE PROTECCIÓN OFICIAL. 10. ARBITRIO SOBRE SOLARES SIN EDIFICAR. 11. ARBITRIO SOBRE SOLARES EDIFICADOS Y SIN EDIFICAR: FORMA DE VAlORAR. 12. DERECHOS Y TASAS: ALCANTARILlado EN NUEVO EDIFIcIO. - IX. JURISDICCION CONTENCIOSO - ADMINISTRATIVA: 1. Previo pago de la cantidad liquidada. 2. Falta de previo pago: LIOUIDACIONES aNULADAS POR EL TRIBUNAL ECONÓMICO-ADMINISTRATIVO Provincial.-X. MONTES: Derecho real de aprovechamiento de 
MADERA POR PARTE DEL VECINDARIO: PLANES DASOCRÁTICOS.-XI. MONUMENTOS HISTORICO-ARTISTICOS: ACTUACIÓN DE La DIREcción GENERAL de BEllas ARTES.-XII. POLICIA MUNICIPAL: 1. Edificios RUINosos. 2. EDIfICIOS RUINosos: competencIa. 3. EDIfICIOS RUINoSOS: LEGITIMACIÓN PARA PEDIR TAL DECLARACIÓN. 4. EDIFICIOOS RUINOSOS: INFORMES TÉCNICOS. 5. EDIFICIOS RUINOSOS: INMINENCIA DE RUINA.

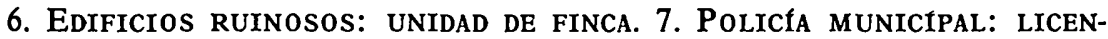
CIAS. 8. POLICfA MUNICIPAL: LICENCIAS: MONUMENTOS HISTÓRICO-ARTÍSTICOS.-XIII. TERMINOS MUNICIPALES: INCORPORACIÓN FORZOSA DE Municipios: facultades de la AdMinistración del Estado.XIV. URBANISMO: Planes PARCIALES: DOCUMENTOS PRECISOS.XV. ZONA MARITIMO-TERRESTRE: CONCESIONES: OPOSICIÓN DEL AYUNTAMIENTO: PROCEDIMIENTO.

\section{ASOCIACIONES}

\section{Junta Vecinal Agropecuaria: competencia}

En razón y concordancia con la sentencia de esta Sala de 15 de febrero del corriente año, que decidió el recurso ejercitado por la «Junta Vecinal Agropecuaria de Telledon, en caso absolutamente idéntico, y donde se emplearon iguales tesis a las aquí esgrimidas por el Ayuntamiento de Pola de Lena, autoridades intervinientes en la vía administrativa y las partes recurrentes, por eso no hay otro remedio que reproducir lo ya declarado por este Tribunal en virtud de unidad de doctrina para no incidir en infracción del artículo 102 de la Ley Jurisdiccional; de ahí la viabilidad de reconocer que los fines estatutarios concernientes al recurso, en su redacción escueta y genérica indicada en el segundo razonamiento de esta sentencia, no pueden entenderse excluyentes ni contradictorios de las funciones atribuidas por la Ley a entidades públicas -artículos 101 b) y 102 a) de la Ley de Régimen local, por ejemplo-, por lo que $a b$ initio, resulta imposible interpretar aquellos fines actuantes sobre montes públicos y autorizados como lícitos, en el amplio sentido anejo a su simple enunciado de «Guardería Rural» y "Ordenación del pastoreo", lo que equivaldría a atribuirse un ilícito monopolio contradictorio de las funciones públicas concurrentes; así pues, descartada esta hermenéutica omnicomprensiva de los fines lícitos autorizados, deben entenderse limitados a subordinación y colaboración con las autoridades y sólo operativos entre los asociados como corresponde a la constitución privada de la entidad; de donde se sigue de lo expuesto que no cabe en modo alguno que esa Asociación se atribuya o asuma competencia y funciones de derecho público, ya que tampoco integra una Entidad menor constituida con arreglo al artículo 23 y siguientes de la calendada Ley de Régimen local, ni la jurisprudencia que se cita por la demandante en la pretensión postulada no incluye entre las Entidades menores que especifica a Asociaciones de ninguna especie; por tan- 
to, lo verificado, al ser contrario a lo fijado en los Estatutos por que se rige la Junta, y a la Ley, es consecueintemente ilícito. (Sentencia de 23 de octubre de 1973, Ar. 4.132).

\section{BIENES}

\section{Reversion: el artículo 97 del Reglamento de Bienes de las ENTIDADES LOCALES}

Considerando: Que aunque efectivamente el artículo 97 referido no establece distinción alguna, lo que abonaría su aplicación a todas las transmisiones verificadas por una Entidad local, es preciso corroborar esta interpretación inicial con otros medios interpretativos dada la trascendencia del problema, debiendo partirse para ello de los siguientes datos: $1 . \circ$, el artículo 97 al hablar de cesiones sugiere la duda de si emplea este término como equivalente a cesión gratuita, ya que anteriormente se alude con separación a los actos de enajenación, gravamen y permuta (artículo 95, I) y a las cesiones gratuitas (artículo 95, 2 y 5; artículo 96, I), pero esta apreciación se desvanece completamente ante el supuesto contemplado en el artículo 96, 2, que regula la cesión de solares al Instituto Nacional de la Vivienda para construir viviendas de renta reducida, cesión que revestirá normalmente, según el precepto, la forma de permuta de los terrenos por el número equivalente de aquéllas y cuando esto no fuera posible, la de cesión gratuita; $2 .^{\circ}$, esta ambivalencia del término cesión para los actos a título gratuito y a título oneroso no es extraña a otras leyes, y así en la del Suelo de 12 de mayo de 1956 se refiere al término cesión a ambos títulos en su artículo 153 y en el 155 a la enajenación por precio, y el Reglamento del Patrimonio del Estado de 5 de noviembre de 1964 se refiere la palabra cesión a la venta en sus artículos 146 y 147, y finalmente en relación con el artículo 96 del propio Reglamento de Bienes de las Entidades locales, la Orden de 21 de septiembre de 1955, dictada para su interpretación, alude en su artículo $4 .^{\circ}$ a la cesión de terrenos mediante precio cuando no fuere practicable el procedimiento normal de permuta a que se refiere dicho precepto; $3 .^{\circ}$, el evidente criterio finalista que inspira el artículo 97 que se está interpretando, tanto puede darse en las transmisiones gratuitas como en las onerosas, pues la Corporación cedente pudo tener en cuenta el destino de los bienes al enajenarlos mediante precio ya a efectos urbanísticos generales como para lograr la instalación o mejora de algún centro de especial interés para el Municipio; y $4 . .^{\circ}$, de los anteriores extremos, de carácter gramatical, sistemático y finalista, debe llegarse en su completa integración a la convicción de la necesidad de aplicar la norma a todo supuesto de transmisión, sea a título oneroso o gra. tuito, en que se dan los requisitos previstos en ella, y a esta conclusión en definitiva se ha llegado por este Alto Tribunal en las sentencias de la Sala $4 .^{a}$ de 25 de septiembre de 1970 y 13 de noviembre de 1972 al 
referir a dicho precepto los efectos que en aquel caso se pactaron para lograr la reversión de bienes municipales cedidos mediante precio al no haberse respetado los plazos pactados por los compradores, pues si bien en ambas sentencias operaba el efecto del pacto no dejan de hacer referencias al modo automático de operarse la reversión según la repetida norma para desvanecer las alegaciones del comprador en contra del efecto automático, fundando la de 25 de septiembre de 1970 en su $4 .^{\circ}$ considerando el efecto automático de la reversión en estar estipulada y en ser preceptiva reglamentariamente.

Considerando: Que al decidir la procedencia de la aplicación del efecto reversional del repetido artículo 97 a los actos a título oneroso, resta todavía decidir si en el caso presente se dan los supuestos fácticos previstos en la norma, o sea, la consideración finalista que impropiamente denomina condición, y a la vista de los ya examinados antecedentes y documentos unidos a la propia escritura de venta, que se otorga según el último de los antecedentes "según el expediente de su razón", hay que llegar a la conclusión de que la venta tuvo por finalidad decisiva para el Ayuntamiento transmitente la instalación de las dependencias ministeriales ya referidas, finalidad que trasciende de un mero móvil interno o puramente subjetivo para causalizarse de modo claro, e incluso necesario, al determinar la obligada autorización del Ministerio de la Gobernación para dicha finalidad concreta, que no puede separarse del efecto transmisivo de la venta, por lo que su frustración acarrea la aplicación de la reversión al haber transcurrido más de siete años cuando se adopta el acuerdo municipal, hecho suficientemente acreditado en el expediente, siendo también de tener en cuenta que el precio fijado para la venta fue sensiblemente inferior al de otras ventas de solares próximos según certificación obrante en autos, extremo que evidencia más aún la consideración causalista de la finalidad prevista al vender el solar, lo que determina la procedente aplicación de esta norma reversional que tiende a proteger los patrimonios municipales, a lo que tampoco faltan alusiones en el preámbulo del Reglamento de Bienes de las Entidades locales que se está interpretando. (Sentencia de 16 de noviembre de 1973, Ar. 4.107).

\section{CALIFICACIÓN JURfDICA: ALTERACí́N}

CONSIDERANDo: Que aunque la alteración de la calificación jurídica de los bienes de las Entidades locales sea una declaración de voluntad formal administrativa, como afirma el primer considerando de la sentencia recurrida, no puede caber duda que ello ha de ser a través de un expediente regulado reglamentariamente, como exige el artículo 8 del Reglamento de Bienes de las Corporaciones locales de 27 de mayo de 1955, en cuyo precepto se requiere la demostración de la convenioncia de tal cambio de afectación; y es claro que en el caso de autos a la vista del expediente administrativo instruido al efecto no solamente no 
se ha demostrado dicha conveniencia, sino ni siquiera se ha alegado, con lo que la infracción del artículo invocado es palmaria y constituye razón evidente para anular los acuerdos en que se plasmó el cambio de destino impugnado. (Sentencia de 11 de junio de 1973, Ar. 2.865).

\section{CONTRATACION ADMINISTRATIVA}

\section{Gastos DE FORMALIZACIÓN DEL CONTRATO}

En la contratación administrativa local, a tenor del artículo 47 del Reglamento de 9 de enero de 1953, los gastos de formalización del contrato, incluso los honorarios del Notario autorizante, son de cuenta del contratista, precepto, sin embargo, del que se apartó el Ayuntamiento demandado para asumir, contra el texto inequívoco de citado artículo, la mitad de las mismas, y que, como erróneamente arguye la defensa municipal, se trasladó sobre el contratista un gasto que en otro caso hubiera tenido que soportar el Ayuntamiento, pues este parecer se funda en la equivocada creencia de que el precepto aplicable es el artículo 1.455 del Código Civil.

4. Que desde la base cierta de que los "gastos" que se ocasionan con motivo de la formalización del contrato, incluso los honorarios del Notario autorizante, son, según el artículo 47 citado, a cargo del contratista, no puede ofrecer duda que los contratantes, mediante la cláusula de que "los gastos» que origina la otorgación del presente documento (esto es, el de formalización del contrato) serán satisfechos por mitad, se refierieron a los que dice el artículo 47, y alterando con este contenido contractual lo que manda la norma reglamentaria, se cargó sobre la Administración el pago de la mitad de estos gastos - sobre lo que no existe contienda-, mas no los que no son de formalización del contrato; y como las del Impuesto sobre transmisiones, a cargo del recurrente, no se integran en indicado concepto, no quedaron comprendidas en la cláusula contractual, cláusula que significó, según se ha dicho, que el contratista pague la mitad de los gastos que dice el artículo 47 , y no la totalidad como dispone el mismo. (Sentencia de 2 de octubre de 1973, Ar. 3.900).

\section{VENTA DE UN TERRENO MUNICIPAl al ESTADo: contrato ADMINISTRATIVO}

Considerando: Que a lo largo de todo el procedimiento administrativo seguido para llegar al acuerdo municipal de venta del solar, así como del seguido en el Ministerio de la Gobernación reflejado en el Decreto autorizando la venta directa sin el trámite de subasta y finalmente en el acta de afectación del solar adquirido para el Ministerio de la Vivienda, se reitera de modo constante que el destino del solar que 
se adquiere es la construcción de un edificio para la Delegación del Ministerio de la Vivienda, por lo que conforme a criterio doctrinal seguido en la jurisprudencia hay que afirmar la naturaleza administrativa del contrato de venta del solar cuyo inequívoco destino a un servicio público le confiere ese carácter, no pudiendo desconocerse esa finalidad, aunque en las cláusulas del contrato no se haga mención expresa de la misma cuando consta reiteradamente en los antecedentes que se insertan en la escritura y en las certificaciones que se unen a la misma e igualmente resulta de la propia intervención de los dos otorgantes que ostentan las respectivas representaciones de organismos administrativos, estando especialmente autorizados para dicho otorgamiento, por lo que tanto desde el aspecto subjetivo, que en este caso es doble, como en orden a la finalidad que se pretende alcanzar a través del contrato, hay que concluir que es de naturaleza administrativa, criterio que ha sido mantenido por este Alto Tribunal, entre otras, en sus sentencias de 25 de septiembre de 1970 y de 13 de noviembre de 1972, ambas de la Sala Cuarta del mismo, por cuyas razones es improcedente declarar inadmisible el presente recurso. (Sentencia de 16 de noviembre de 1973, Ar. 4.107).

\section{CONTRIBUCION TERRITORIAL}

CONSTRUCCIÓN DE EDIFICIO POR UN CONCESIONARIO SOBRE TERRENO MUNICIPAL

Si sobre un terreno municipal fue construido un edificio por el concesionario que había de dedicarlo a lonja y mercado público durante cuarenta años, al término de cuyo plazo habría de pasar a propiedad municipal, la contribución territorial corresponde pagar al citado concesionario. (Sentencia de 4 de octubre de 1973, Ar. 3.505).

\section{EXPROPIACION FORZOSA}

\section{INTERESES}

Considerando: Que respecto a la segunda de las cuestiones planteadas en este recurso de apelación, la relativa a la imposición al organismo expropiante de los intereses legales, es preciso para resolver sobre ella establecer dos premisas fácticas: A) En cuanto a la fecha inicial de su cómputo, que por tratarse de expropiación urgente, por imperativo del artículo 52, regla 8.a, de la Ley de Expropiación forzosa, ha de fijarse como fecha inicial el devengo de intereses legales el 26 de noviembre de 1959, siguiente al día en que, según consta en el acta correspondiente, tuvo lugar la ocupación de la finca por el organismo de la 
Administración expropiante. B) Respecto a la dualidad de intereses, los legales y los de demora, habida cuenta que esta Sala, en las sentencias de 25 de enero y 15 de febrero de 1965, 30 de abril y 5 de mayo de 1966 y 25 de septiembre de 1971, ha declarado la incompatibilidad de la percepción de ambos conceptos por gozar los primeros de preferencia y quedar subsumidos en ellos los de demora, hemos de declarar la improcedencia de la pretensión de devengo de estos últimos. (Sentencia de 22 de noviembre de 1973, Ar. 4.209).

\section{JUSTIPRECIO: CRITERIOS DE VALORACIÓN}

La cuestión planteada en esta apelación se reduce a si han de apli. carse, a la expropiación de que se trata, los criterios valorativos, establecidos en el capítulo $4 .^{\circ}$ del Título $20^{\circ}$ de la Ley del Suelo; al no ser la construcción del Instituto Politécnico Superior ejecución de planes de vivienda y urbanismo ni de obra propiamente municipal, no son obligatoriamente aplicables tales criterios impuestos por la Ley 52/62 y Decreto $343 / 63$, sino que han de seguirse los de la Ley de Expropiación forzosa, incluida la facultad concedida en el artículo 43 para no seguir las normas tasadas de valoración y sí las más adecuadas para llegar a fijar el verdadero justiprecio, en armonía con los valores reales de los bienes que se expropian. (Sentencia de 2 de octubre de 1973, Ar. 3.479).

\section{JUSTIPRECIO: FECHA A LA QUE HA DE REFERIRSE}

Considerando: Que la doctrina del Tribunal Supremo, reiterada entre otras, en sus sentencias de 13 de marzo y 26 de noviembre de 1969 y 4 de marzo de 1970, que cuando el retraso en la fijación del justiprecio alcanza tan largo período de tiempo que durante el que media entre él y el momento inicial del expediente de expropiación, el bien expropiado ha experimentado una tan notable alza que, notoriamente, no puede cubrirse con la fijación del interés legal previsto en la propia Ley, entonces es obligado remitir la valoración al momento del justiprecio, toda vez que en otro caso la demora debida al incumplimiento de la Administración de los artículos 21,25 y, en su caso, el 52 de la Ley de Expropiación forzosa, conduciría a la injusta solución de privilegiar a quien, con facultades para ello, aplicó irregularmente el procedimiento expropiatorio en perjuicio del propietario expropiado ajeno a toda culpa en aquella larga demora. (Sentencia de 31 de octubre de 1973, Aranzadi 3.887). 


\section{JUSTIPRECIO: INDEMNIZACIÓN A INQUILINO DE VIVIENDA}

2. Que la Ley de Arrendamientos urbanos vigente, que en su artículo 114 recoge como causa novena de resolución del contrato la expropiación forzosa del inmueble, dispone al mismo tiempo que la indemnización de la Administración a los inquilinos o arrendatarios nunca será inferior a las establecidas en la Sección $2 .^{a}$, Capítulo $8 .^{\circ}$, de la propia Ley, y dentro de esa Sección, al regular las indemnizaciones, cuando se trata de viviendas, en sus artículos 66 y 67, contempla distintos supuestos, señalando módulos fijos para cada uno de ellos, que van desde el importe de la renta de dos anualidades hasta el de seis mensualidades, pero cuya aplicación no es rigurosa o inalterable, pues permite al arrendatario que hubiere desalojado la vivienda dentro del año siguiente a la fecha del requerimiento reclamar dentro de los tres meses al desalojo mayor indemnización de aquella expresada, justificando que los perjuicios son superiores. Sistema éste de la posibilidad de una indemnización no fija coincidente con el mantenido en la Ley de Expropiación al permitir al Jurado de Expropiación, en el artículo 43, llevar a cabo la tasación aplicando los criterios estimativos que juzgue más adecuados cuando considere que el precio obtenido, sujetándose a las reglas fijas establecidas en la misma Ley, resulta notoriamente inferior o superior al valor real de los bienes y derechos objeto de la expropiación; y no se diga que esa facultad no es aplicable cuando se trata de indemnizaciones al arrendatario de fincas expropiadas, porque este supuesto se prevé en el artículo 44 de la Ley y aquél se refiere a los contemplados en los artículos que le preceden, puesto que es en el Reglamento desarrollando la Ley donde, aclarando cualquier duda que pudiera surgir por esa colocación numérica del caso de los arrendatarios, dispone expresamente la posibilidad de aplicar a las indemnizaciones a ellos referentes lo determinado en el citado artículo 43 de la Ley; extremo éste que resulta también aclarado en el mismo sentido por reiterada jurisprudencia del Tribunal Supremo, de la que son muestra, entre otras, las sentencias de 15 de febrero y 3 de mayo de 1965, 27 de junio de 1966 y 4 de octubre de 1969, ésta precisamente referida a un caso de inquilinato o arrendamiento de vivienda. (Sentencia de 13 de octubre de 1973, Ar. 3.574).

\section{JUSTIPRECIO： INDEMNIZACIÓN JUSTA}

La indemnización justa es aquella que sea suficiente para adquirir otro bien análogo al que por la expropiación se priva. (Sentencia de 29 de octubre de 1973, Ar. 3.869). 


\section{JUSTIPRECIO: LEGALIDAD APLICABLE: COLEGIO}

Se plantea como cuestión primordial a resolver la decisión sobre qué criterios han de ser los aplicables en la valoración de las fincas objeto de la expropiación para la construcción de un colegio nacional de 24 secciones en la ciudad de San Fernando, si los de la Ley del Suelo o los contenidos en la Ley de Expropiación forzosa. Al disponer la Ley del Suelo en su artículo $1 .^{\circ}$ que es objeto de la presente Ley la ordenación urbanística de todo el territorio nacional, concretando en el número 2.0 los aspectos a que se refiere la actividad urbanística, entre ellos la ejecución de las urbanizaciones, y el 3.० confiere la facultad en su apartado $b$ ) de expropiar los terrenos y construcciones necesarios para efectuar las obras y cuantos convengan a la economía de la urbanización proyectada, se está refiriendo en todo momento a la ordenación urbanística y a las expropiaciones que tengan como finalidad ejecutar las urbanizaciones proyectadas, por lo que las que se refieren a cualquier otra obra de utilidad pública o social no se encuentran comprendidas en esta Ley, ni en la 52/1962, cuyo ámbito es (como dice su artículo 1..$^{\circ}$ la ejecución de los planes de vivienda y urbanismo; como en el presente caso no está acreditado que la expropiación se lleve a efecto en ejecución de los planes de urbanización, sino que se desprende que su finalidad es la construcción de una unidad escolar, ha de llegarse a la conclusión de que los criterios a seguir para determinar el justiprecio de estas fincas no son los marcados en la Ley del Suelo, sino los de la de Expropiación forzosa, como se ha venido manteniendo por esta Sala en sentencias, entre otras (para casos análogos), de 14 de febrero de 1968, 2 de noviembre de 1970, 11 de noviembre de 1971 y 2 de los corrientes. (Sentencia de 17 de octubre de 1973, Ar. 3.636).

\section{JUSTIPRECIO: TRASLADO DE NEGOCIO: PÉRDIDA DE BENEFICIOS}

Considerando: Que la simple lectura del acuerdo del Jurado en su particular de "pérdida de beneficios durante el período de traslado» evidencia que únicamente fue tenida en cuenta la disminución de ingresos ocurrida a partir del inicio de traslado hasta el momento de instalación en el nuevo local; pero sin incluirse los beneficios perdidos desde este instante hasta aquel en que la clientela se estime normalizada, los cuales han venido siempre considerados indemnizables, en los casos de expropiación que afecte a negocio o industria con traslado de sus actividades a otra sede, por la jurisprudencia de esta Sala, sentencias, entre otras, de 19 de junio de 1968, 3 de julio de 1971, 18 de noviembre de 1972 y 8 de octubre actual. Por tanto, la sentencia apelada aplicó correctamente la citada doctrina jurisprudencial y los artículos 1, 36, 43 y 44 de la Ley de Expropiación forzosa, imponiéndose, en consecuencia, la desestimación del recurso. (Sentencia de 31 de octubre de 1973, Aranzadi 3.888). 


\section{JUSTIPRECIO: TRASLADO DE VAQUERIA: INDEMNIZACIONES}

Indemnizaciones comprenden los capítulos pecuniarios valorados por la Administración y el recurrente en sus respectivos informes, escrito de alegaciones, demanda y contestación. Estos capítulos son tres: 1, gastos generales de transporte e instalación; 2, pérdida de beneficios desde el inicio del traslado hasta la normalización de la industria en el nuevo establecimiento, y 3, gastos por la mayor renta de locales que como arrendatario habrá de abonar el interesado. (Sentencia de 8 de octubre de 1973, Ar. 3.527).

\section{NECESIDAD DE OCUPACIÓN: NO ES RECURRIBLE EL ACTO MUNICIPAL DECLARÁNDOLA}

Al tratarse de resoluciones sobre la necesidad de ocupación de la finca del recurrente, decretada por Corporación a quien le está atribuida la competencia para tomar tal acuerdo, y basada en un provecto de obras municipal que por sí mismo implica la declaración de utilidad pública, resulta totalmente inadmisible su examen ante esta jurisdicción, por expresa disposición del párrafo 3. ${ }^{\circ}$ del artículo 22 de la Ley de Expropiación forzosa. (Sentencia de 2 de octubre de 1973, Ar. 3.478).

\section{FUNCIONARIOS}

\section{DeREChos pasivos: aCtualización DE PENSIONES}

CONSIDERANDo: Que en esencia, lo que el presente recurso se debate no es otra cuestión que la consistente en determinar si en la actualización de pensión de viudedad causada por funcionario de la Administración local, y que se fijó con arreglo a la legislación aplicable en la época de su señalamiento en un 25 por 100 del sueldo regulador, ha de ser mantenido dicho porcentaje o, por el contrario, debe aplicarse el 45 por 100 establecido por los Estatutos de la Mutualidad Nacional de Previsión de la Administración Local, cuestión planteada en forma reiterada ante esta Sala, que en numerosas sentencias, y entre ellas las de 14 de octubre de 1970, 27 de enero de 1971, 1 de marzo de 1972 y 22 de junio del presente año, declaró que al efectuarse la actualización de pensiones a tenor de la Ley 108/1963, de 20 de julio, y Orden de 22 de abril de 1964, el porcentaje aplicado al señalarse la primitiva pensión ha de mantenerse por imperativo de la disposición 2. ${ }^{a}$ de la referida Orden, por lo que, acreditado que en el presente caso dicho porcentaje fue del 25 por 100 del sueldo regulador, no resultan ajustadas a derecho las resoluciones del Ministerio de la Gobernación hoy impugnadas que 
lo alteraron señalando el 45 por 100 para la pensión de doña Antonia $P$. y en su consecuencia deben ser revocadas con estimación del presente recurso. (Sentencia de 6 de dicimbre de 1973, Ar. 4.368).

\section{ACTUALIZACIÓN DE PENSIONES: CómpUto DE QUINQUENIOS}

CONSIDERANDo: Que la resolución recurrida, al incluir el noveno quinquenio en el regulador de la pensión de viudedad de doña Catalina G. P., aunque para fijar la de jubilación de su esposo, funcionario que fue del Ayuntamiento de Vitoria durante cuarenta y cinco años y cinco meses, se tuvieron en cuenta sólo los ocho quinquenios por que cotizaba, es conforme a derecho y no incurre en la irregularidad que se aduce en la demanda, pues al cesar en el servicio dicho funcionario estaba vigente para el régimen de quinquenios la prohibición de que se reconociesen más de ocho, establecida en el artículo 330 de la Ley de Régimen local, y en atención a ello, naturalmente, ni al fijar la jubilación del causante ni anteriormente en su situación de actividad a efectos de cotización podía incluirse, pese a sus años de servicio, el noveno quinquenio, mas fallecido el jubilado en 18 de enero de 1969, la limitación de quinquenios para el regulador de la viudedad había desaparecido, a virtud de lo dispuesto en el artículo 10 de la Ley $108 / 63$ y en la norma 2. ${ }^{\text {a de las }}$ que para su ejecución contiene la Orden de 22 de abril de 1964, ya que esa eliminación del límite es aplicable no sólo a las pensiones que causen los funcionarios que se encontraban en activo cuando se dictó, sino también a las causadas por funcionarios cesados con anterioridad y que han de actualizarse conforme al citado artículo 10 de la Ley 108/63, pues en otro caso, como dice la sentencia de 29 de enero de 1968, recaída en supuesto análogo al presente, "quedaría incumplido el espíritu informador de toda la legislación de actualización de pensiones, que pretende, según expresa y reiteradamente afirma, que en cuanto sea posible quienes desempeñaron el mismo empleo con igual categoría, clase y años de servicio no reciban derechos pasivos en cuantía desigual por el simple hecho de haberlos prestado en distintas épocas". (Sentencia de 28 de noviembre de 1973, Ar. 4.220).

\section{ACTUALIZACIÓN DE PENSIONES: GRAN INVALIDEZ}

CONSIDERANDO: Que la cuestión debatida en este recurso se concreta a determinar si en la actualización de una pensión pasiva dc jubilación forzosa a consecuencia de gran invalidez, cuya cuantía se fija en el apartado $c$ ) del artículo 40 de los Estatutos de la Mutualidad Nacional de Previsión de la Administración Local en el 150 por 100 del haber regulador, ha de mantenerse este porcentaje o ha de limitarse al 100 por 100 , en aplicación del artículo 10 de la Ley $108 / 63$, de 20 de julio, y apartado B) de la norma 4.a de la Orden de 22 de abril de 1964. 
Considerando: Que, como expresa la resolución recurrida, mientras no se modifique la calificación de la invalidez ha de de mantenerse el porcentaje que de conformidad a los Estatutos corresponde sobre el haber regulador, ya que los mismos constituyen la norma aplicable de conformidad con la Ley de creación de la Mutualidad y del artículo 10 de la Ley 108/1963, de 20 de julio, por lo que ha de ser declarado el acto recurrido conforme con el Ordenamiento jurídico y, por tanto, desestimado el recurso, en cumplimiento del artículo 83,1 ), de la Ley reguladora de esta jurisdicción. (Sentencia de 11 de diciembre de 1973. Aranzadi 4.442).

\section{DeREchos Pasivos: SERVICIOS EVENTUALES}

Considerando: Que la resolución del Ministerio de la Gobernación de 16 de abril de 1970 es impugnada por la M. U. N. P. A. L., alegando que infringió el ordenamiento jurídico al estimar que por el cálculo de las prestaciones que corresponde por viudedad a doña Valentina G. H., han de tenerse en cuenta los servicios eventuales que prestó su esposo al Ayuntamiento de Zaragoza, careciendo de fundamento tal impugnación, por cuanto el causante de la pensión tenía el carácter de afiliado obligatorio a la Mutualidad en el momento de su constitución y la Orden del Ministerio de la Gobernación de 2 de abril de 1964 en su apartado 5-2 da el mismo tratamiento a los servicios eventuales que a todos los demás prestados por el funcionario, procediendo en consecuencia la desestimación del recurso, de conformidad además con lo resuelto por esta Sala en reiteradas sentencias, como las de 10 y 17 de octubre, 30 de noviembre y 19 de diciembre de 1968 y la de 20 de febrero de 1969. (Sentencia de 5 de noviembre de 1973, Ar. 3.909).

\section{GOBERNADORES CIVILES}

\section{DEMOLICIÓN DE VIVIENDAS: AUDIENCIA DE LOS INQUILINOS}

ConsIDERANDo: Que es doctrina jurisprudencial reiterada - sentencias, entre otras, de 18 de mayo de 1965, 17 de abril de 1970, 9 de junio de 1972- la que sostiene que el ejercicio de la facultad de autorizar derribos de edificios habitados otorgada a los Gobernadores civiles por los artículos 78, 79 y 81 de la Ley de Arrendamientos urbanos viene conatcionuda, no solo por factores de oportunidad de discrecional apreciación, sino también -y principalmente- por otros que constituyen el presupuesto básico del ejercicio de tal facultad, vbg. posibilidad legal de la reedificación, etc., y que hace que nos encontremos ante un supuesto típico de actividad reglada que de un lado exige que el acto de autorización sea motivado por imperativo del artículo 43, 1, a), de la Ley de Procedimiento administrativo, y de otro, que la autorización, 
como acto administrativo, sea remate o decisión final de un procedimiento administrativo que se inicia con la petición del particular-propietario, en el que han de cumplirse los trámites o fases legalmente previstos con la finalidad de lograr una resolución fundada, tal como sostuvo ya la sentencia de la Sala de 18 de mayo de 1964, al decir que de conformidad con lo preceptuado en el artículo $1 .^{\circ}$, número $1, \mathrm{y}$ disposición final $1 .^{\mathrm{a}}$, en el inciso último de sus números $1 .^{\circ}$ y $3 .^{\circ}$, de la Ley de Procedimiento Administrativo en conexión con lo dispuesto por el artículo 21 del Decreto de 10 de octubre de 1958, los procedimientos administrativos que se tramiten de conformidad con lo establecido por la Ley de Arrendamientos urbanos tienen que ajustarse a las normas contenidas en la Ley de Procedimiento administrativo.

CONSIDERANDO: Que abundando en las razones dadas por la sentencia apelada en sus considerandos $4 .^{\circ}$ y $6 .^{\circ}$ y tal como señalaron las sentencias de este Tribunal de 28 de febrero de 1969 y 15 de enero de 1973, "la audiencia» de los interesados en un procedimiento administrativo es un trámite esencial susceptible de ser cumplido de diversas formas de acuerdo con las caracteristicas o finalidades de la actividad administrativa, pero que, en todo caso, su omisión merece la conceptuación legal de infracción grave de procedimiento, causante de nulidad si la misma genera «indefensión». (Sentencia de 13 de noviembre de 1973, Aranzadi 4.329).

\section{SANCIONES POR FALTAS A LA MORAL}

ConsIDERANDo: Que la utilización válida de la potestad sancionadora atribuida por el artículo 260, apartado $i$ ), a los Gobernadores civiles en defensa de la moral y disciplina de costumbres requiere la apreciación y expresión de hechos concretos y específicos, susceptibles de ser calificados como infracción de tales normas morales o constitutivas de escándalo público, por lo que la mera expresión genérica de observar conducta inmoral o haber dado lugar a escándalo sin apoyarla en la realidad concreta y especifica de unos determinados hechos es insuficiente para justificar en Derecho el uso de dicha potestad sancionadora, puesto que de tal modo se priva al posible infractor de los medios de defensa en demostración de la inexistencia de los presuntos actos que quedan asi desconocidos e ignorados. (Sentencia de 9 de octubre de 1973, Aranzadi 3.970 ). 


\section{HACIENDAS LOCALES}

\section{ARBITRIO DE PLUSVALIA: EXENCIONES: PRIMERAS TRANSMISIONES DE TERRENOS RESULTANTES DE OBRAS DE SANEAMIENTO Y MEJORA INTERIOR DE GRANDES POBLACIONES}

ConsIDERANDo: Que en relación con la segunda cuestión en que se basa la sentencia apelada consistente en estimar referida y aplicable la exención concedida por el apartado $f$ ) del número $10^{\circ}$ del artículo 520 de la Ley de Régimen local a los solares resultantes de la ejecución de un plan de urbanismo tramitado conforme a la Ley del Suelo, que entiende ser el supuesto que concurre en el caso de autos, en que las obras realizadas lo fueron a través de un Plan Parcial Especial, que no impide puedan también calificarse de obras de saneamiento y mejora de una población, debiendo por ello quedar exentas del arbitrio las transmisiones operadas por la recurrente, aunque se estimase producido el supuesto de hecho del arbitrio, por aplicación del referido apartado f) del número 1 del artículo 520, es de observar que este precepto que ciertamente declara exentas las primeras transmisiones de solares resultantes de las obras de saneamiento y mejora interior de grandes poblaciones, en primer lugar sólo alcanza a los solares, circunstancia que no consta concurrir en todo el terreno o terrenos transmitidos por "Urmenor, S. A.», puesto que era preciso para que se pudiera calificar como transmisión de un solar, conforme al artículo 499, que todo él tuviera línea de fachada a calle urbanizada; en segundo lugar, que tal solar sea resultante de obras de saneamiento y mejora interior de una población, a las que en modo alguno pueden equipararse las obras de extensión que tienen por finalidad urbanizar sectores o zonas situadas fuera del casco urbano de la población, como son las comprendidas en la zona sur de la Manga del Mar Menor de Cartagena, pertenecientes a dicho término municipal, pero fuera del casco y de su ensanche, puesto que se trata de la urbanización de la zona sur de la Manga del Mar Menor, y, por último, hay que referir la exención a que las obras se hayan hecho al amparo de la legislación especial dictada para reglar esas obras de saneamiento y mejora de las poblaciones, concretamente la Ley de 18 de marzo de 1895 y el Real Decreto de 15 de diciembre de 1896, que fueron las que concedieron esa exención del impuesto de incremento de valor de los terrenos para el caso de que tales obras se hayan ejecutado a costa del transmitente, pero que no se puede extender por analogía dicha exención a los supuestos de urbanizaciones efectuadas al amparo de la Ley del Suelo y cuyas obras no son de mejora y saneamiento interior de una población, ya que tampoco el Ayuntamiento de Cartagena las autorizó al amparo de aquella Ley de 1895, ni la Ley del Suelo, a diferencia de la Ley Castellana de 1953, incorporó a su regulación la aplicación de las exenciones establecidas en dicha Ley de 1895, pues para los supuestos de urbanizaciones ejecutadas bajo 
el régimen de la Ley del Suelo ya ésta prevé en sus preceptos los beneficios fiscales a que tendrán derecho sus titulares, y como en esta materia de exenciones fiscales ni a las Corporaciones locales les está permitido declarar otras que las concretamente previstas y autorizadas en la Ley de Régimen local, ni es jurídicamente válida la interpretación analógica para extender más allá de sus términos estrictos el ámbito de las exenciones y bonificaciones, por lo que tampoco es acertada la segunda base en que se apoya la sentencia apelada al declarar que, en el caso de estimarse producido el supuesto de hecho del arbitrio, la deuda tributaria quedaba excluida por aplicación de la exención establecida en el artículo $520,1 .^{\circ}, f$ ) de la Ley de Régirnen local. (Sentencia de 26 de junio de 1973, Ar. 2.764).

\section{ARBITRIO DE PLUSVALIA: INDICE TRIENAL DE VALORES; IMPUGNACIÓN}

Considerando: Que el artículo 94, apartado $c$ ), de la Ley Jurisdiccional preceptúa que las sentencias de las Salas de lo Contencioso-Administrativo serán susceptibles de recurso de apelación, salvo las que se dictaran, entre otros asuntos, en los de aprobación y modificación de las Ordenanzas sobre exacciones de las Corporaciones locales.

Considerando: Que en virtud de lo expuesto, como quiera que el objeto del recurso es precisamente aquel a que se refiere el apartado c) del citado artículo 94 -porque, como ya ha declarado esta Sala, en su sentencia de 18 de noviembre de 1972, "una racional interpretación de lo que establece el artículo 511 de la Ley de Régimen local, al decir que las valoraciones se harán públicas juntamente con la Ordenanza del Arbitrio, y serán impugnables, igual que éstas, ante el Delegado de Hacienda, permiten afirmar que Ordenanza e Indice forman un todo impugnable»-, claro es que la cuestión que se debate en «litis» consecuentemente incide en la admisión del recurso de apelación interpuesto, por lo que de oficio, por su naturaleza y por afectar al Orden Público Procesal debe declararse mal admitida dicha apelación, sin que se aprecien motivos para una especial imposición de costas. (Sentencia de 30 de octubre de 1973, Ar. 3.911).

\section{ARbitrio de plusvalía: el Instituto Nacional de Colonización ESTÁ SUJETO AL ARBITRIO}

Tampoco puede prevalecer la doctrina de que el Instituto Nacional de Colonización estaba exento de este arbitrio de plusvalía por aplicación de lo que dispone el artículo 520, apartado $a$ ), de la misma Ley de Régimen local; la sentencia del Tribunal Supremo de 30 de octubre de 1971 entiende que al tener dicho Instituto personalidad jurídica propia e independiente de la del Estado, según los artículos 2 y 3 del 
Decreto de 21 de noviembre de 1947, no le es extensiva la exención del arbitrio sobre el incremento del valor de los terrenos, establecido en el artículo antes citado de la Ley de Régimen local, a favor del Estado, ya que el artículo 1 de la Ley de Régimen jurídico de la Administración estatal proclama la personalidad jurídica única de la misma, la cual está integrada por distintos órganos ordenados jerárquicamente, con lo que la posible diversidad de sujetos de relaciones jurídicas en tales órganos será obstáculo para la incardinación dentro de la Administración del Estado, al surgir entonces verdaderas entidades que pasarían a formar parte de la llamada Administración institucional, con la consecuencia de poder litigar entre sí, al igual que frente al Estado mismo, lo que no sería procesalmente factible en el caso de tratarse de meros órganos administrativos privados de personalidad, conclusión que viene abonada por el artículo 2 de la Ley de Entidades estatales autónomas y por los artículos 3, apartado E, letra $c$ ), y 35 de la Ley reguladora de esta Jurisdicción, de igual modo que abonan la interpretación estricta del concepto Estado, que emplea el artículo 520, a), de la Ley de Régimen local, los artículos 719 y 721 de la misma Ley y el propio artículo 32 del Decreto de 21 de noviembre de 1947, que se limita a decir que el Instituto Nacional de Colonización gozará de cuantos beneficios y exenciones fiscales le fueren concedidos por las Leyes Tributarias correspondientes entre los que no se encuentra una que le exima del arbitrio municipal de que ahora se trata. (Sentencia de 5 de noviembre de 1973. Aranzadi 4.013).

\section{ARbitrio de plusvalfa: ReCTIFICACIÓN DE liQUidaCIONES; ERROR DE DERECHO}

Considerando: Que precisamente por haber apreciado que los erro res que han justificado las segundas liquidaciones son de derecho, es por lc que en la sentencia apelada se confirma el acuerdo de 31 de enero de 1971 del Tratado Económico-administrativo provincial, desestimando en consecuencia el primero de los recursos promovidos por el referido Ayuntamiento; apreciación del todo correcta, puesto que la equivocación sobre el valor de los terrenos, más que pender del hecho físico de la localización del terreno, corresponde a la calificación valorativa del mismo, esto es, a su clasificación dentro de las zonas y valores establecidos en el pertinente cuadro de la Ordenación municipal del Arbitrio.

CoNSIDERANDo: Que si esa primera equivocación es de naturaleza jurídica, eso mismo ocurre, e incluso de forma más acusada, con la segunda, relativo al comienzo del período impositivo, porque el que el mismo se retrotraiga al año 1966, como se decretó en tan repetidas primeras liquidaciones, o, por el contrario, a 1946 o 1952, no depende de un puro cálculo cronológico, sino de la naturaleza jurídica que se atri- 
buya al acto de adjudicar en pago, de su haber en la disuelta sociedad de ganancias, a doña Astrid B. G., viuda de S., los terrenos de los que proceden los vendidos a doña Teresa V. P., origen del supuesto tributario que nos ocupa, pues cualquiera que sea la solución a que se llegue sobre el alcance de la disolución de la sociedad legal de gananciales, respecto del cual en el propio caso de autos se han producido tesis contradictorias, lo que no cabe la menor duda es que los interrogantes que puedan existir sobre esta cuestión son esencialmente de condición jurídica, puesto que sólo a través del estudio de la naturaleza jurídica del acto divisorio de la comunidad matrimonial y de la subsiguiente adjudicación de bienes, puede llegarse a la conclusión procedente. (Sentencia de 20 de noviembre de 1973, Ar. 4.146).

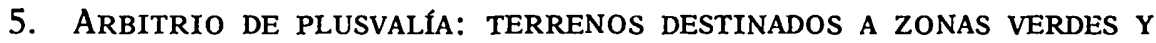 VIALES EN URBANIZACIÓN}

Debemos sentar como punto de partida para llegar a la decisión correcta alcanzada por la sentencia recurrida, la afirmación de que por dicho contrato se efectuó una transmisión equivalente fiscalmente a la del dominio de todo el terreno que se sujetó a la liquidación del arbitrio comprendido tanto el de la parcela $a$ ) como el de la parcela $b$ ), pues la condición de que la superficie de la parcela $b$ ) se cederá gratuitamente por el enajenante al Ayuntamiento con destino a viales y zona verde no se realizó ni puede hacerse, pues, con independencia de las acciones que la Ley reserve al comprador, la expresada condición, por llevar aneja una modalidad onerosa para el Ayuntamiento de Pamplona, cual es el destino a viales y zona verde del polígono, sólo podía aceptarse por dicha Corporación previo expediente conforme a lo dispuesto en el artículo 10-2 del Reglamento de Bienes, y resultar de la mencionada escritura de enajenación de $10^{\circ}$ de octubre de 1970 y del escrito de alegaciones formulado por el Ayuntamiento de Pamplona en el recurso de alzada interpuesto ante la Diputación Foral de Navarra, que el Ayuntamiento de Pamplona es un tercero ajeno a las estipulaciones practicadas en la escritura y la cesión no fue aceptada por el Ayuntamiento ni se tramitó el expediente impuesto por el Reglamento municipal, no cumpliéndose con ninguna de las formalidades que exige la contratación con las Corporaciones locales, por lo que no existiendo vehículo contractual alguno que obligue al Ayuntamiento a aceptar aquella cesión, unido a que en la cláusula 2.a se transmite al comprador el dominio de lo que está debajo de la superficie de la parcela $b$ ), es manifiesto que a los efectos fiscales de la exigibilidad del arbitrio de plusvalía la referencia que se haga a una cesión de superficie no aceptada es irrelevante. (Sentencia de 18 de junio de 1973, Ar. 2.724). 


\section{ARbitrio de Plusvalfa: TERRENos SUJETos}

El objeto del arbitrio de plusvalía lo constituye el aumento de valor que los terrenos experimenten, con carácter general, por la acción ge. neralizada de la Administración municipal dentro del término, por lo que no es válido alegar que por razón de que no se haya concretado la acción municipal en la zona en que esté sito el terreno transmitido, no es de aplicar el arbitrio, pues basta que sea un terreno sito en el término del Municipio. (Sentencia de 30 de noviembre de 1973, Ar. 4.277).

\section{Arbitrio de plusvalía: terRenos No suJETos; CARga de la PRUEBA}

Respecto a la segunda cuestión, también planteada y reiterada en esta apelación referente a la no sujeción al arbitrio de los terrenos sometidos a la tasa de equivalencia, por tratarse de una explotación agrícola y minera, es de puntualizar, como ya tantas veces lo viene reiterando esta Sala, que, dados los términos del número 1 del artículo 510 de la Ley de Régimen local en relación con el 516 de la misma, en principio están sometidos al pago del arbitrio de plusvalía todos los terrenos del término municipal - siendo la no sujeción la excepción-que sólo se da cuando en los terrenos sometidos a ese gravamen concurra alguna de las circunstancias descritas en aquel precepto, por lo que era al interesado a quien incumbía la prueba de la explotación agrícola o minera existente durante el período impositivo, prueba que no se hizo, por no ser válido, legal ni económicamente, confundir la naturaleza o destino agrícola de una finca con la existencia real y efectiva de una explotación que exige la demostración de un capital y trabajo puesto por la empresa en actividad para la explotación de la finca o terrenos, y de la prueba practicada no resulta que los referidos terrenos están incorporados activamente a una explotación, como así lo apreció la propia sentencia apelada en su quinto considerando al afirmar que no está demostrada tal alegación, es decir, que estén afectos los terrenos a una explotación de las señaladas para exceptuarlos del gravamen, siendo indistinto o intrascendente que los mismos o alguno de ellos por lindar con la carretera por uno de sus frentes reúna la condición de solar, concepto que sólo entraría en juego para el pago del arbitrio pero no para la exención o no sujeción al mismo. "Cerámica Guisasola" es una industria de fabricación de estos productos que aunque haya sido incluida en el Censo de explotaciones para el régimen de la Seguridad Social Agrícola esto sólo fue a efectos de incluirla en una matrícula fiscal correspondiente a una exacción distinta, pero que no por ello demuestra que realmente exista una explotación agrícola ni una explotación minera. (Sentencia de 5 de noviembre de 1973, Ar. 4.015). 


\section{ARbitrio de Plusvalfa: terrenos destinados a viales}

ConsIDERANDo: Que esta Sala ha declarado reiteradamente - sentencias de 17 de diciembre de 1971, 22 de junio de 1972, 7 de marzo de 1973, etc.- que los terrenos destinados en los planes de ordenación urbana a vías públicas, siempre que dichos planes contengan las debidas y detalladas alineaciones, no están sujetos al arbitrio de plusvalía, porque esta particularidad los hace carentes de incremento de valor para sus titulares, desapareciendo la causa y razón justificativa del tributo, ya que además en el caso de que no se realice el proyecto de urbanización o el terreno pierda su carácter de inedificable resultan nuevamente sometidos al gravamen, mas no puede entenderse esta exclusión con el sentido restrictivo que pretende el Ayuntamiento apelante, que sostiene que únicamente si el suelo está comprendido en un proyecto de urbanización queda exceptuado del arbitrio, sin que baste el hallarse integrado en un Plan General, pues la doctrina jurisprudencial mencionada lo que exige es que sea legalmente posible precisar el terreno que ha sido destinado a viales y que en su día puede estar sometido a la obligación de cesión de dicha superficie, con arreglo a los artículos 67 y 114 de la Ley del Suelo, y este extremo puede conocerse no solamente cuando una zona está ordenada por un Plan Parcial, que con arreglo al artículo 10.1, c, de la Ley de 12 de mayo de 1956 debe necesariamente contener las alineaciones y características de las vías que en la misma se han de trazar, sino también cuando el Plan General es lo suficientemente detallado y determina las alineaciones y los viales, ya que, como los posteriores planes parciales y los proyectos de ejecución de obras de urbanización no pueden modificar el Plan General, se produce la debida concreción de esta superficie. (Sentencia de 5 de noviembre de 1973, Ar. 4.014).

\section{ARbitrio de plusvalfa: viviendas de PROTECCIÓN OFICIAL}

Considerando: Que única cuestión planteada en la presente "litis» es la referente a si la transmisión de los terrenos de autos goza o no de la bonificación del 90 por 100 del arbitrio sobre incremento del valor de los terrenos; así determinadas las recíprocamente contrapuestas apreciaciones de las partes, el primer razonamiento del recurrente para impugnar la resolución recurrida es que en la inicial escritura de adquisición no se hizo constar'el destino de los terrenos para la construcción de viviendas de protección oficial, olvidando el Ayuntamiento recurrente, cuando así razona, que con notoria anterioridad a la fecha de 30 de marzo de 1971, en que por él se practicó la liquidación de plusvalía, ya habían tenido lugar tanto la escritura de aclaración de 8 de abril de 1968, subsanando el defecto de méritos, como el perfecto conocimiento que del destino de tales terrenos tiene el Ayuntamiento a través del per- 
miso de construcción al efecto otorgado y de la devolución de los derechos que origina, en atención precisamente al destino de los terrenos dichos, lo cual desembocā en la inoperancia de este primer motivo de oposición al acto recurrido, y sin que la precedente conclusión desvirtúe el contenido doctrinal de las sentencias del Tribunal Supremo de 18 de diciembre de 1969 y 12 de noviembre de 1970, dictadas en interpretación del artículo 31 del Reglamento de 24 de junio de 1955, que exigía que en el contrato de adquisición de los terrenos figurase la constancia de la "exclusividad" de construir en ellos viviendas de renta limitada, exigencia dulcificada en la redacción del actual artículo 43 del nuevo Reglamento de 24 de julio de 1968, lo que dio lugar al criterio jurisprudencial que queda recogido en la moderna sentencia de 31 de marzo de 1971. (Sentencia de 12 de noviembre de 1973, Ar. 4.052).

\section{ARBitrio SOBRE SOLARES SIN EDIFICAR}

El arbitrio sobre solares sin edificar, a tenor del apartado $10^{\circ}$ del artículo 499 de la Ley de Régimen local, exige para sujetar el gravamen a un terreno que éste reúna la condición de solar; es claro que la fecha inicial del devengo no podrá ser anterior a aquella en que la parcela de terreno adquirió esa cualidad, y como aparece acreditado que la finca de los recurrentes sita en la antigua Avenida de la Luz, número 9, hoy Alberto Alcocer, con fachada a esta vía, fue parcialmente expropiada por el Ayuntamiento y precisamente en su colindancia con esa avenida para realizar obras de ampliación y urbanización de la misma, resulta evidente que hasta la incorporación de la parte expropiada urbanizada a la vía, el resto de la fínca no expropiada careció de línea de fachada a vía urbanizada, requisito indispensable según el citado precepto de la Ley de Régimen local para que a efectos del arbitrio se pueda atribuir a un terreno la condición de solar, ya que perdió la colindancia con la vía pública por la expropiación comenzada en 1962 y consumada el 3 de octubre de 1964, sin que la recobrase hasta que la superficie expropiada se integró, mediante las obras de urbanización, en la nueva calle así ensanchada, con lo que se cumplió la finalidad de la expropiación, por lo cual, según el citado artículo 499, apartado 1, hasta ese momento no pudo originarse la obligación de tributar. (Sentencia de 8 de octubre de 1973, Ar. 5.339).

\section{ARBITRIO SOBRE SOLARES EDIFICADOS Y SIN EDIFICAR: FORMA DE VALORAR}

CONSIDERANDo: Que en orden al sistema de valoración adoptado por el Ayuntamiento, que el ya citado artículo 590-5. de la Ley de Régimen local se remite, en cuanto a la base del arbitrio y determinación del valor corriente en venta, a las disposiciones reguladoras del arbitrio 
ordinario sobre solares sin edificar, remisión que hace aplicable también para el arbitrio de solares edificados y sin edificar, que da lugar al recurso, el artículo 500, según el cual los solares objeto del arbitrio, los valores bases del mismo, las personas obligadas al pago y la extensión superficial habrán de constar en un Registro municipal de Solares, cuya formación comprenderá las operaciones que puntualiza, y cuyo Registro, una vez aprobado reglamentariamente, será la base de la matrícula de contribuyentes, según el artículo 507.

Considerando: Que la Administración municipal, apartándose de tales normas, decidió optar por el sistema de determinar el valor de la parcela de referencia tomando las cifras del Indice de valores formado por el Ayuntamiento de Madrid a efectos del arbitrio municipal sobre incremento de valor de los terrenos, lo cual supone una clara infracción de los artículos de la Ley de Régimen local que mencionados quedan, si nos atenemos a la doctrina de las sentencias de esta misma Sala de 10 de marzo, 7 de abril y 6 de diciembre de 1972 y también de la que pronunció la Sala $4 .^{a}$ en 4 de julio de 1959. (Sentencia de 22 de junio de 1973, Ar. 2.726).

\section{DERECHOS Y TASAS: alcantaRILlado EN NUEVo EDIFICIO}

ConsIDERANDo: Que con esta interpretación tan restrictiva el Tribunal a quo exonera a la aludida sociedad del pago de una tasa, no obstante darse el supuesto de hecho habilitante de su devengo, puesto que concurre la circunstancia de la existencia de un nuevo edificio, que viene a reemplazar a otros dos antiguos, pero con un volumen de edificación, y, por tanto, con una densidad de moradores notablemente superior al de aquéllos (oficinas de una entidad bancaria, 28 apartamentos y cinco viviendas suntuarias, frente a seis viviendas de las edificaciones derruidas), lo que tiene su correspondiente traducción económico-fiscal, representada por la diferencia en más del nuevo líquido imponible cifrado en la cantidad de pesetas 1.361.943, que a su vez corresponde a una situación en la que el desagüe de la nueva casa implica una utilización del alcantarillado general en mayor cantidad que el antiguo, y con ello un mayor beneficio, lo cual configura el hecho tributario, porque, previo a todo esto, aparece como realidad incuestionable la existencia de lo que viene a ser la esencia de esta figura impositiva: la acometida al referido alcantarillado de este nuevo desagüe, a lo que no se opone el que se haya podido utilizar la de uno de los dos edificios anteriormente existentes en el mismo solar, porque este simple hecho material carece de virtualidad suficiente para neutralizar los factores positivamente concurrentes de la nueva autorización, que es el acto tipificado en la Ordenanza, basado en la habilitación legal, para el devengo de la tasa que nos ocupa; autorización que se otorga o se deniega, que constituye un acto administrativo, que, a su vez, deriva de unas deter- 
minadas actuaciones, en las que debe intervenir el competente servicio técnico, encargado de controlar las condiciones en que tal acometida se realiza y tomar nota del previsible desaguie que la nueva edificación ha de provocar. (Sentencia de 4 de octubre de 1973, Ar. 3.502).

\section{JURISDICCION CONTENCIOSO-ADMINISTRATIVA}

\section{Previo pago de la cantidad liquidada}

Considerando: Que en relación al requisito del previo pago es de ratificar, en su integridad, la doctrina sentada en la sentencia de la Sala de 14 de junio de 1973, como ultimación del proceso argumental iniciado por las sentencias de 12 de febrero de 1972 (al calificar de norma en blanco el apartado e) del artículo 57.2 de la Ley) y 12 de marzo de 1973 (norma de reenvío), y que de nuevo ratifica con rango legal el apartado 4 del artículo 132 de la Ley de 17 de marzo del corriente año, al concretar que el requisito dicho ha de venir impuesto precisamente por una norma con categoría de ley (vbg.: ártículo 87.2 de la Ley de Montes de 8 de junio de 1957; artículo 21.4 de la Ley de Orden público de 30 de julio de 1959, modificada en 21 de julio de 1971; artículo 32 de la Ley de 20 de julio de 1963; artículo 37 del texto refundido de la Ley de Viviendas de protección oficial de 24 de julio de 1963); exigencia que, por el contrario, no imponen tanto la Ley General tributaria como el artículo 727, apartado 4, de la Ley de Régimen local, por lo que en materia de exacciones locales la reciente modificación de la Ley Jurisdiccional refuerza el principio de que el requisito del previo pago sólo será obstáculo para la admisión del recurso contencioso, cuando expresamente se exija por alguna otra ley que regule materialmente las $\mathrm{Ha}$ ciendas locales y que ante el hecho jurídico de su existencia conduce a la no admisión de la excepción de inadmisibilidad que la sentencia apelada acoge al amparo del apartado $f$ ) del artículo 82 en conexión con el apartado 2 e) del artículo 57 de la Ley Jurisdiccional. (Sentencia de 27 de junio de 1973, Ar. 2.765).

\section{Falta de previo Pago: liquidaciones anUladas por el Tribunal Económico-Administrativo Provincial}

Considerando: Que por lo que respecta a la causa de inadmisibilidad aducida por el Ayuntamiento apelante, tanto en primera como en segunda instancia - no haberse acompañado al escrito de interposición del recurso el correspondiente documento acreditativo del pago del importe de las cuotas liquidadas de «litis», tal alegación debe, ante todo, rechazarse en el presente pleito, a la luz de lo establecido, entre otras, en la sentencia de esta Sala de 11 de febrero de.1971 - sentencia dictada 
en recurso de indudable analogía con el actual en este extremo-, puesto que anuladas las referidas liquidaciones por el Tribunal EconómicoAdministrativo Provincial falta ya en este caso a los referidos efectos el necesario débito líquido procedente del acto económico-administrativo impugnado que es presupuesto condicionante del meritado pago del importe liquidatorio, sin que el hecho de haberse formulado el recurso contencioso-administrativo pueda revitalizar las liquidaciones anuladas -recuérdese lo dispuesto en el artículo 116, número $3 .^{\circ}$, del Reglamento de 26 de noviembre de 1959- y menos en el presente supuesto controvertido en que dichas liquidaciones anuladas lo fueron, no sólo por motivos concomitantes distintos del que sirve de base al procedimiento contencioso-administrativo, sino por motivos sobre todo plenamente consentidos por las partes y muy en especial por el propio Ayuntamiento recurrido, hoy promovente de esta apelación. (Sentencia de 23 de junio de 1973, Ar. 2.729).

\section{MONTES}

\section{DERECHO REAL DE APROVECHAMIENTO DE MADERA POR PARTE DEL VECINDARIO: PLANES DASOCRÁTICOS}

Petición que ha de ser examinada en dos puntos fundamentales, el primero el que los derechos que puedan asistir a terceros interesados no se refieren a tales, sino muy concretamente a copartícipes en el aprovechamiento, los vecinos de Cobeta, puesto que, a virtud de sentencia del Tribunal Supremo, que queda ya citada, son titulares juntamente con la entidad reclamante de un derecho limitativo del dominio y, en segundo lugar, habría de tenerse en cuenta que el concepto "dasocráticon de un monte se refiere o ha de referirse lógicamente a la totalidad de aprovechamiento de un bosque, no sólo por la descripción de la voz, según el diccionario de la Real Academia (parte de la dasonomía, que trata de la ordenación de los montes a fin de obtener la mayor renta anual y constante, dentro de la especie, método y turno de beneficio que se hayan adoptado; definiéndose la "Dasonomía" como ciencia que trata de la cría, conservación, cultivo y aprovechamiento de los montes), sino por su etimología (dasocracia, de daysos, bosque; y kratos, poder: dasonomía de bosque y nomos, ley), o sea, norma del bosque como conjunto, como campo poblado de árboles o matas, y no sólo en su posibilidad maderable; de modo que, ante todo, se ofrece la pro puesta de un Plan de Ordenación de Montes que sólo ha sido redactado por el titular del dominio sin conocimiento de los titulares de derechos reales limitativos de la propiedad; y además el Plan se dirige al apro vechamiento de resinas con olvido de los demás elementos de riqueza económica que el bosque encierra, con lo que se hace necesario que el Plan sea conocido y aceptado por el Ayuntamiento de Cobeta como premisa necesaria para que la Administración estatal pueda aprobarlo, ya 
que en otro caso se daría un contrasentido en cuanto a la legitimación de naturaleza real para su formalización, bien entendido que el monte está catalogado como de utilidad pública de la Provincia de Guadalajara al número 126-A del Catálogo; y como quiera que el artículo 202 del Reglamento de Montes previene que el aprovechamiento de los productos forestales ( $y$ aprovechamientos forestales son todos) en los montes públicos y en los de propiedad privada, se realizarán dentro de los limites que permitan los intereses de su conservación y mejora, de acuerdo con cuanto se dispone en este título (título de aprovechamientos forestales, dentro del Libro II de los aprovechamientos o industrias forestales), resulta clara la potestad administrativa con arreglo a los artículos 29 y 30 de la Ley de Montes, de 8 de junio de 1957, de intervenir en la regulación de este aprovechamiento, que en realidad no se ha denegado por la estimación de derechos civiles de las partes interesadas en el disfrute, sino por cuanto ( $y$ al margen de todo posible sentido de desviación de poder) la Administración ha entendido, acertadamente, a juicio de la Sala, y dentro de lo que dispone el artículo 211 del Reglamento ya citado, que los Planes no satisfacen los objetivos de conservación y restauración de las masas forestales, en el orden de la tutela estatal a que se refiere la exposición de motivos de la Ley, dada la innegable y beneficiosa proyección de estos bienes en los intereses nacionales, razón que abona la presencia con arreglo a derecho de los actos cuya anulación se pretende. (Sentencia de 5 de junio de 1973, Ar. 2.690).

\section{MONUMENTOS HISTORICO-ARTISTICOS}

\section{Actuación de la Dirección General de Bellas Artes}

Es reglada la actuación de la Dirección General de Bellas Artes en orden a permitir o no que sea demolida una ermita que no está catalogada como monumento histórico-artístico. (Sentencia de 6 de noviembre de 1973, Ar. 4.018).

\section{POLICIA MUNICIPAL}

\section{EDIFICIOS RUINosos}

CONSIDERANDo: Que la declaración del estado de ruina de un edificio regulada en el artículo 170 de la Ley del Suelo comprende tres supuestos diferentes, independientes entre sí, que no precisan simultanea o conjunta concurrencia para producir sus efectos, pues basta la existencia de cualquiera de ellos para conseguir la declaración de ruina del edificio al que afectan, según ha declarado con reiteración el Tribunal Supremo, entre otras sentencias, en las de 10 de diciembre de 1963 , 
15 de noviembre y 18 de diciembre de 1971 , siendo también doctrina jurisprudencial que la declaración de ruina no exige la existencia de un peligro inminente, para el que el ordenamiento ya prevé el uso de las medidas pertinentes, sino que basta que exista un peligro más o menos inmediato para las personas o las cosas, subsumible en cualquiera de los apartados del artículo 170 de la citada Ley del Suelo para que deba declararse la situación de ruina (sentencias de 18 de diciembre de 1971 y las citadas en ella), destacando que para dar lugar a la ruina de un edificio como comprendido en el apartado a) del artículo 170 invocado - cuando el daño no sea reparable técnicamente por medios normales- es necesario que las medidas sean anormales o extraordinarias, es decir, que no se ajusten a las reglas corrientes de conservación $y$ reparación de construcciones - sentencias de 11 de abril y 21 de octubre de 1967-, ya que cuando hay que sustituir elementos estructurales, más que medidas de conservación se está en una verdadera función reconstructiva, aunque sea parcial - sentencia de 15 de marzo de 1972-. (Sentencia de 6 de junio de 1973, Ar. 2.746).

\section{EDIFICIOS RUINOSOS: COMPETENCIA}

Sexto: Que entrando en el examen de los acuerdos municipales dictados en el segundo expediente municipal («diligencias de urgencia», las denomina el Ayuntamiento en alguna ocasión), hay que tener presente que, ciertamente, el artículo 170-4 de la Ley del Suelo (y también los artículos 101-h y 117- $b$ y $d$ de la Ley de Régimen local, según ha entendido la jurisprudencia - sentencias de 10 de febrero de 1958 y 23 de septiembre de 1963 y otras-) atribuye a los Alcaldes la función, dentro de una policia de seguridad, de adoptar, en caso de fundado temor de daños a las personas o a los bienes, medidas de seguridad respectó de los edificios; pero estas medidas, que han de ser las necesarias y responder a una situación de urgencia y peligro que no permita la espera hasta que se resuelva el expediente de ruina, tienen que tener un carácter preventivo y provisional; y por esto podrá la Administración disponer el desalojo con el carácter meramente cautelar que dice el Tribunal Supremo en la citada sentencia de 23 de septiembre de 1963 y las demoliciones en lo estrictamente necesario para evitar el peligro, o las medidas de apuntalamiento tendentes a aquella finalidad preventiva, dentro siempre de este objetivo cautelar - sentencia de 17 de octubre de 1970-, mas lo que desborda el ámbito del artículo 170-4 es imponer a los propietarios obras de reconstrucción $y$, en suma, las que tengan un carácter definitivo, ni aun acudiendo a lo que dice el artículo 168-2 de la Ley del Suelo; pues este precepto, en cuanto define el deber de conservación a cargo de los propietarios, tiene unos limites, fuera de los cuales no pueden imponer a su cargo el que asuman la ejecución de unas obras (artículo 169-2). (Sentencia de 11 de octubre de 1973, Ar. 3.583). 


\section{EDIFICIOS RUINOSOS: LEGITIMACIÓN PARA PEDIR TAL DECLARACIÓN}

Que alegan los arrendatarios de la finca de autos, al contestar la demanda, que el instante del expediente administrativo no ha acreditado ni intentado probar su condición de dueño, lo que estiman es determinante de que el recurso sea declarado inadmisible; pero tal alegación no puede merecer ser acogida, ya que el artículo 170 de la Ley del Suelo establece, en términos amplios, quiénes tienen la posibilidad de pedir la declaración de ruina, al decir que el Ayuntamiento podrá declararla bien de oficio o a instancia de cualquier interesado, y no se puede negar que el instante tenía interés en el asunto, dada su condición de condueño, cuando es la propia Corporación la que le ha venido requiriendo a llevar a cabo la cubrición del edificio, en concepto precisamente de tal carácter; $y$ sabido es, por otra parte, que cualquier comunidad puede actuar en beneficio de la comunidad (sentencias del Tribunal Supremo de 24 de octubre de 1903 y 4 de abril de 1921). (Sentencia de 11 de octubre de 1973, Ar. 3.583).

\section{EDIFICIOS RUINOSOS: INFORMES TÉCNICOS}

CONSIDERANDO: Que según una muy reiterada jurisprudencia del Tribunal Supremo, en materia de ruina debe prevalecer el criterio de los técnicos, y tanto la Administración, al dictar su acuerdo, como posteriormente la Sala de lo Contencioso, al revisar su legalidad, deben estudiar detenidamente tales informes, decidiendo en consonancia con lo dictaminado en ellos, llegando alguna sentencia a precisar que ni la Administración ni las Salas de lo Contencioso tienen otro margen de actuación que el de aquilatar y ponderar el valor de los informes, pues el presupuesto al que la norma condiciona la declaración de ruina es, en lo sustancial, técnica perteneciente a la ciencia de los técnicos de la construcción, correspondiendo a sus conocimientos emitir un juicio sobre "daños reparables", "costas de reparación" $y$ "valor del edificio", que son los datos a tener en cuenta al decidir - sentencias de 12 de febrero de 1970, 27 de enero de 1966, 7 de mayo de 1963 y 3 de febrero de 1961, entre otras muchas-; junto a tales puntualizaciones jurisprudenciales deben también ser tenidas en cuenta aquellas otras que dan preferencia a los informes emitidos por los peritos de titulación superior sobre los que emitan otros con título de inferior calidad (debiendo prevalecer, pues, los informes de los Arquitectos sobre los de los Aparejadores) y las que declaran que el dictamen de los técnicos municipales tienen más fuerza que las emitidas por aquellos otros peritos que dictaminaron a solicitud de las partes interesadas, los cuales pudieran no sustraerse de los intereses privados en pugna, de los que, en cambio, están alejados los técnicos municipales, doctrina ésta que por lo reiterada y conocida es ocioso citar. (Sentencia de 26 de octubre de 1973, Aranzadi 4.279). 


\section{EDIFICIOS RUINOSOS: INMINENCIA DE RUINA}

Considerando: Que del examen del expediente aparece cómo la finca en cuestión, y siguiendo no sólo el informe del Arquitecto de la propiedad que se acompaña a la denuncia, sino el informe del Arquitecto municipal, cuya objetividad no es objeto de duda, la finca, en conclusión, amenaza ruina con riesgo de daño inminente para las personas y las cosas y considera que procede, con carácter de urgencia, el desalojo de ocupantes para iniciar con las debidas precauciones las obras de demolición, con lo que aparece que, como ajustado a derecho el acto por el cual el Alcalde, con arreglo a sus facultades, legalmente reconocidas, dicta su disposición en este punto concreto y está ajustada a derecho la actuación municipal que utiliza la facultad excepcional correspondiente a autoridad competente para ejercitar este procedimiento extraordinario y no seguir el expediente contradictorio de declaración de ruina que supone lenta tramitación de naturaleza distinta, apta para los casos en que no exista la inminencia que en este caso se declara. (Sentencia de 7 de junio de 1973, Ar. 2.750).

\section{EDIFICIOS RUINOSOS: UNIDAD DE FINCA}

Considerando: Que en cuanto al problema de si son varias edificaciones contiguas, pero independientes - tesis de la parte apelante-, 0 , por el contrario, se trata de construcciones que forman parte integrante del conjunto edificado - tesis de la Corporación municipal y del coadyuvante, que comparte la sentencia de primera instancia-, de lo actuado hay sobrados elementos de juicio para concluir que constituye en realidad una edificación unitaria, pues aunque compuesta de elementos construidos en diferentes épocas, todos los cuerpos que la integran tienen porciones comunes, principalmente en la cubierta, de donde se deduce su unidad arquitectónica y en su virtud, por tratarse de un solo inmueble a los efectos de su declaración de ruina, ésta debe ser total y no parcial, siguiendo la constante doctrina en este sentido del Tribunal Supremo -cuyas sentencias por conocidas releva de su cita-, y donde se sienta que la diferenciación de partes distintas en el edificio objeto de la ruina en modo alguno implica separación de cuerpos o autonomía de zonas de edificación, sino que cuando no se dan, como en este caso sucede, tales supuestos de independencia, separación y autonomía entre los diversos cuerpos arquitectónicos integrantes del inmueble, se impone entender que el mismo constituye una unidad predial a efectos del concepto unitario técnico de la declaración administrativa de ruina. (Sentencia de 17 de octubre de 1973, Ar. 4.050). 


\section{Policta MUNicipal: LiCENCIAS}

No es imprescindible para obtener la licencia de nueva construcción el que se tenga la de demolición de las edificaciones alli existentes, puesto que desde luego ya antes de empezar a construirse en dicho solar se procederá a su derribo con la licencia correspondiente. (Sentencia de 28 de septiembre de 1973, Ar. 3.457).

\section{Policfa MUNICIPAL: LICENCIAS: MONUMENTOS H ISTÓRICO- ARTísticos}

Considerando: Que los artículos 3, 23, 33, 34 y concordantes de la Ley del Patrimonio Artístico Nacional de 13 de mayo de 1933, en conexión con lo dispuesto en el artí́xulo 6 del Decreto de 22 de julıo de 1958 y preceptos concordante;, tal como han sido interpretados, entre otros, por la sentencia de la Sala de 24 de mayo de 1973, atribuyen o apoderan a la Dirección General de Bellas Artes de facultades de tutela o fiscalización en materia de policía de la construcción referida a zonas urbanas sometidas a su control: poblaciones declaradas. monumentos o conjuntos histórico-artísticos o que posean zonas monumentales determinadas, que como se recalca en la citada sentencia de la Sala se atribuye propiamente al Centro directivo dicho una competencia compartida con las Corporaciones locales respectivas, pero sin posibilidad de mezcla o confusión, pues lo más que puede sostenerse es que se manifiestan superpuestas, dado que la realización de una obra $\mathrm{u}$ otra actividad intervenida en tales zonas exige las dos autorizaciones o licencias: la estatal y la municipal, que han de ser otorgadas (como actividad reglada que es) conforme al derecho objetivo que rige en cada caso, y ello aunque en la práctica pudiera seguirse la vía del expediente único al amparo del artículo 39-1 de la Ley de Procedimiento administrativo, si bien en este caso resulta evidente que en el expediente municipal de licencia debe constar el informe técnico y en su caso la autorización de la Dirección General que en su día se transforma en ingrediente del acto complejo que realmente es el acto que resuelve un procedimiento de este tipo; mas también ocurre, y ésta parece ser la regla general (dadas las dudas de aplicación de tal precepto de la Ley de Procedimiento a la esfera local, la simple atonía perceptible en la actuación de los órganos administrativos en materia de cooperación, etcétera), que los administrados logran en expediente independiente la autorización estatal, por entender, conforme al criterio clásico, que ésta es presupuesto de la licencia municipal, pero que también, y en todo caso, "no prejuzga, sustituye ni enerva las potestades municipales» (sentencia de 20 de mayo de 1961) que le vienen atribuidas en su específico ordenamiento. (Sentencia de 8 de octubre de 1973, Ar. 3.540). 


\section{TERMINOS MUNICIPALES}

\section{INCORPORACION FORZOSA DE MUNICIPIOS: FACULTADES DE LA} ADMINISTRACIÓN DEL EsTado

Considerando: Que partiéndose en el presente caso de no estarse en presencia de una fusión voluntaria de los Municipios interesados, sino de la incorporación forzosa del de Berriatúa al de Ondárroa, cuyo expediente se inició de oficio, por resolución del Gobierno Civil de Vizcaya, de 24 de noviembre de 1965, convalidada posteriormente por la Dirección General de Administración Local, no ofrece duda que la normativa legal vigente en la materia está constituida por los artículos 12 , número $1 .^{\circ} ; 13$, apartado $c$ ); 14 y 20 , número $1 .^{\circ}$, de la Ley de Régimen local, y $4 .^{\circ}$, número $1 .^{\circ} ; 8 .^{\circ}$, números $1 .^{\circ}, 2 .^{\circ}$ y $3 .^{\circ}, 14$ y 24 del Reglamento de Población y Demarcación territorial de las Entidades locales, exigiéndose en todas estas preceptivas legales referidas que se den notorios motivos de necesidad o conveniencia económica o administrativa para poder procederse a la incorporación de los Municipios afectados y estableciéndose por reiterada doctrina de esta Sala, en síntesis, entre otras, en sentencias de 18 de marzo de 1959, 7 de julio y 30 de noviembre de 1960, 1 de marzo y 13 de mayo de 1966, que: "cuando la Administración central actúa de oficio con objeto de incorporar un Municipio a otro por razones de necesidad o conveniencia económica o administrativa que asi lo aconsejen, la revisión jurisdiccional del acuerdo de incorporación y el juicio critico sobre su legalidad y procedencia que le sirva de soporte ha de versar sobre la efectiva existencia de tales motivos y su condición de notorios, pero reconociendo y dejando a salvo en todo caso un amplio margen de libertad de apreciación al Consejo de Ministros, pues sólo aquel órgano superior de la jerarquia administrativa puede valorar con acierto las circunstancias de todo orden que en momento y ocasión determinados definen el interés general y conjugar esto con el particular de las Corporaciones afectadas, resolviendo los. eventuales conflictos con criterio ponderativo no sólo de las conveniencias singularmente de indole fiscal del vecindario del Municipio incorporado, sino también y preferentemente del ritmo de expansión urbanística y demográfica del anexionante, teniendo en cuenta la orientación actual de favorecer la concentración de núcleos de población para garantizar la eficiente prestación de los servicios minimos obligatorios como exigencia básica de una decorosa convivencia municipal». (Sentencia de 12 de noviembre de 1973, Ar. 4.328). 


\section{URBANISMO}

\section{Planes Parciales: Documentos PREcisos}

Considerando: Que no puede discutirse, ni las partes lo hacen, que el precepto básico regulador de la formación de tales Planes parciales es el artículo 10 de la Ley del Suelo, de 12 de mayo de 1956, con sus concordantes procesales en ulteriores artículos del mismo texto legal.

Considerando: Que ela Memoria justificativa de la Ordenación, de las etapas para realizarla y de los medios económico-financieros disponibles y que deberán quedar afectos a la ejecución del Plan" faltan en la documentación que integra el texto aprobado e impugnado, dada la envergadura de aquél, en relación con la minuciosidad con que el legislador - para evitar sorpresas perjudiciales así a los intereses públicos como a los legítimos derechos privados afectados- puntualiza las exigencias en cada uno de los documentos que corroboren los extremos que debe comprender el Plan (párrafos $10^{\circ}$ y $2 .^{\circ}$ del artículo 10 citado). (Sentencia de 7 de junio de 1973, Ar. 2.749).

\section{ZONA MARITIMO-TERRESTRE}

\section{CONCESIONES: OPOSICION DEL AYUNTAMIENTO: PROCEDIMIENTO}

Considerando: Que al formular este juicio sobre el carácter o condición de la norma de aplicación en este caso es debido a que la misma establece que en estos supuestos, a diferencia de lo que ordena para otros distintos el otorgamiento de estas concesiones y autorizaciones de obras, requiere el previo informe favorable de los Ministerios de Marina, Comercio e Industria, cuando los establecimientos sean de la competencia de éste "y del Ayuntamiento interesado", con la consecuencia establecida en el ya citado número 8 del propio artículo 10 , esto es, que cuando el Ministerio de Obras Públicas no estime aceptable el informe del Ayuntamiento lo deberá comunicar al mismo y al Ministerio de la Gobernación, y en su caso al de la Vivienda, y de no haber acuerdo entre estos Ministerios y el de Obras Públicas, la decisión corresponderá al Consejo de Ministros, según ya se ha anticipado. (Sentencia de 27 de noviembre de 1973, Ar. 4.273). 